\title{
Assessing Carbon Capture: Public Policy, Science, and Societal Need
}

\section{A Review of the Literature on Industrial Carbon Removal}

\author{
June Sekera ${ }^{1,2,3}$ (i) Andreas Lichtenberger ${ }^{4}$
}

Received: 19 July 2020 / Revised: 1 September 2020 / Accepted: 10 September 2020 / Published online: 6 October 2020 (c) The Author(s) 2020

\begin{abstract}
From typhoons to wildfires, as the visible impacts of climate change mount, calls for mitigation through carbon drawdown are escalating. Environmentalists and many climatologists are urging steps to enhance biological methods of carbon drawdown and sequestration. Market actors seeing avenues for profit have launched ventures in mechanical-chemical carbon dioxide removal (CDR), seeking government support for their methods. Governments are responding. Given the strong, if often unremarked, momentum of demands for public subsidy of these commercial methods, on what cogent bases can elected leaders make decisions that, first and foremost, meet societal needs? To address this question, we reviewed the scientific and technical literature on CDR, focusing on two methods that have gained most legislative traction: point-source capture and direct air capture-which together we term "industrial carbon removal" (ICR), in contrast to biological methods. We anchored our review in a standard of "collective biophysical need," which we define as a reduction of the level of atmospheric $\mathrm{CO}_{2}$. For each ICR method, we sought to determine (1) whether it sequesters more $\mathrm{CO}_{2}$ than it emits; (2) its resource usage at scale; and (3) its biophysical impacts. We found that the commercial ICR (C-ICR) methods being incentivized by governments are net $\mathrm{CO}_{2}$ additive: $\mathrm{CO}_{2}$ emissions exceed removals. Further, the literature inadequately addresses the resource usage and biophysical impacts of these methods at climate-significant scale. We concluded that dedicated storage, not sale, of captured $\mathrm{CO}_{2}$ is the only assured way to achieve a reduction of atmospheric $\mathrm{CO}_{2}$. Governments should therefore approach atmospheric carbon reduction as a public service, like water treatment or waste disposal. We offer policy recommendations along this line and call for an analysis tool that aids legislators in applying biophysical considerations to policy choices.
\end{abstract}

Keywords Biophysical economics $\cdot$ Climate change $\cdot$ Political economy $\cdot$ Energy economics and policy $\cdot$ Public policy · Government

\section{Introduction}

\section{Background}

Electronic supplementary material The online version of this article (https://doi.org/10.1007/s41247-020-00080-5) contains supplementary material, which is available to authorized users.

June Sekera

junesekera@gmail.com

1 Heilbroner Center for Capitalism Studies, New School for Social Research, New York, USA

2 Global Development Policy Center, Boston University, Boston, USA

3 Institute for Innovation and Public Purpose, University College London, London, UK

4 Economics Department, New School for Social Research, New York, USA
As the visible impacts of climate change-from floods to fires to typhoons-continue to mount, calls for mitigation through carbon drawdown are likewise escalating. Environmentalists and many climatologists call for steps to enhance biological methods of carbon drawdown and sequestration. Market actors seeing avenues for profit have launched ventures in mechanical-chemical carbon dioxide removal (CDR), ${ }^{1}$ seeking government support for their methods. Governments are acting and many are adopting policies

\footnotetext{
1 The term "carbon dioxide removal" (CDR) has been widely adopted in the international literature. The term often includes both mechanical-chemical methods and biological methods of carbon drawdown and sequestration. Note that CDR does not include "geo-
} 
and establishing subsidies to support mechanical-chemical methods. Legislators and policymakers in the United States, United Kingdom, parts of Europe, Asia, the Middle East, the European Commission, as well as United Nations-affiliated bodies, have embraced this approach.

Two carbon removal methods have gained significant policy and legislative support: "point-source" capture and storage (known in the literature as "carbon capture/utilization and storage" (CCS/CCUS); and 2) "direct air capture" (DAC) and storage. In this paper, we focus on these methods because they have gained the most traction in the U.S. ${ }^{2}$ and in several other countries, and are being heavily promoted globally (Gunther 2011; Anderson and Peters 2016; Global CCS Institute 2018; Oil and Gas Climate Initiative 2019). We use the term "industrial carbon removal" (ICR) to denote these methods in contrast to biological methods of drawdown through photosynthesis and sequestration in biomass and soils.

The widespread policy and legislative attention to carbon removal among nations has multiple drivers. Most fundamental is the mounting concern about climate change and its widening impacts. Scientists, and increasingly the informed public, have expressed growing alarm about the rising atmospheric concentration of carbon dioxide, which has surpassed 400 parts per million (ppm) from a baseline prior to the industrial era of about $280 \mathrm{ppm}$. Global $\mathrm{CO}_{2}$ emissions have reached nearly $37 \mathrm{Gt}$ annually, a level that scientists warn cannot be sustained, or increased, if we are to avoid exceeding the $1.5-2^{\circ} \mathrm{C}$ threshold of temperature rise identified by the United Nations and the Intergovernmental Panel on Climate Change.

However, there are other drivers as well: scientific reports that proffer "negative emissions technologies" as a mitigation method; appeals by advocates for, and investors ${ }^{3}$ in, commercial carbon removal (Gunther 2011; Gunther 2012a, b; Vidal 2018; Chalmin 2019; Rhodium Group 2019; Chichilnisky 2019; Mufson 2019; Temple 2019a, b; Nagabhushan and Thompson 2019; Diamandis 2019); the influence of fossil fuel interests (Marshall 2019; Morgan 2019; Muffett and Feit 2019; Cresswell 2019; ExxonMobil 2019a;

\footnotetext{
Footnote 1 (continued)

engineering," which refers to interventions, like solar radiation management (SRM), designed to limit the amount of sunlight/energy reaching the planet's surface. Also, note that the term "negative emissions technologies" (NETs) is often used interchangeably with CDR in much of the literature.

2 "The United States leads the world in CCUS deployment today with approximately $80 \%$ of the world's $\mathrm{CO}_{2}$ capture capacity..." https://cleanenergysolutions.org/training/road-map-scale-deployment -carbon-capture-use-storage (Downloaded 4-21-20).

${ }^{3}$ Direct Air Capture investors and ventures include: Bill Gates, Occidental Petroleum, Chevron-Carbon Engineering; Seagram's heir Edgar Bronfman Jr.-Global Thermostat; Gary Comer, Lands End Founder-Kilimanjaro Energy.
}

Tabuchi 2019); the desire to protect jobs in fossil fuels and related construction (Global CCS Institute 2019b; Whitehouse and Slevin 2020; Cusick 2020); advocates for prolonging fossil fuel production (e.g., Nagabhushan and Waltzer 2016; Realmonte et al. 2019) (for example, via "clean coal" and "green oil" (Azzolina et al. 2016; U.S. Dept. of Energy 2017; Hackett 2018); and oil companies seeking to acquire and hold technical patents and intellectual property (Parsons 2018; Soltoff 2019; ExxonMobil 2019b).

Seeing an opportunity for "market solutions," commercial interests, investors, and some research scientists have launched startup businesses to develop and promote chemical-mechanical methods. In addition, fossil fuel interests have moved to reframe an old oil extraction technique ("enhanced oil recovery") as a new climate mitigation method.

In terms of policymaking, government support for ICR goes back decades. German Chancellor Merkel, UK Prime Minister Gordon Brown, and U.S President Obama all worked to advance commercial ICR (The Economist 2009). The U.S. government has provided support since the early 2000s (Schlissel and Wamsted 2018). Between 2010 and 2018 , the U.S. government spent more than $\$ 5$ billion on ICR research and development (Congressional Research Service 2018). In the last 2 years, U.S. congressional attention has increased. Congress expanded an ICR subsidy in 2018. Additional federal subsidies are pending, and several U.S. states also provide or are contemplating financial aid. ${ }^{4}$ The UK's Climate Change Committee issued a report (2019) calling carbon capture and storage "a necessity" and endorsing direct air capture and other engineered and mechanical-chemical methods. The European Union (EU) in 2020 passed the "European Green Deal" to achieve "net zero" by 2050 using methods that include ICR. This legislative trend is important, given that the purveyors of commercial ICR have global ambitions (Oil and Gas Climate Initiative 2019; Gunther 2011). According to the International Energy Agency (2019), "Many countries are increasing their support for CCUS development and deployment, including Canada, China, Japan, the Netherlands, Norway, Saudi Arabia, the United Kingdom and the United States."

In the U.S., public assistance for ICR took flight in the early 2000s on the policy premise of "energy security" (Dooley 2010; U.S. Department of Energy 2016) based

\footnotetext{
4 "Montana, Louisiana, Texas and North Dakota provide tax incentives for CCS deployment" (Page 2020). California's Low Carbon Fuel Standards support CCS and DAC (Townsend and Havercroft 2019). Wyoming enacted legislation in 2020 to advantage coalpowered plants with CCS over renewable power (https://www.wyofi le.com/stripped-of-1b-limit-gordon-carbon-capture-bill-clears-house/ downloaded 4-27-20).
} 
on commercial development of CCS (U. S. Department of Energy 2010). Subsidies were enacted for carbon capture at power plants or industrial emissions sources ("point-source capture"), after which the scavenged carbon would be used for "enhanced oil recovery" $\left(\mathrm{CO}_{2}\right.$-EOR) thereby "increasing domestic oil production" (U.S. Department of Energy 2016). Point-source carbon capture together with $\mathrm{CO}_{2}$-EOR would, it was claimed, reduce the carbon footprint of fossil-fueled energy production. The oil industry has been a prime mover of point-source capture for EOR (Muffett and Feit 2019).

More recently direct air capture (DAC) has taken increasing prominence in both public policy and among investors, especially as the policy premises for carbon capture have morphed into both "climate change mitigation" and "commercial opportunity" - an evolution apparently triggered by reports from the Intergovernmental Panel on Climate Change (IPCC) in 2014 and 2018 (2014b, 2018a). The 2018 report, in particular, presented $\mathrm{CO}_{2}$ removal methods as "pathways" to avoid overshooting the $1.5-2{ }^{\circ} \mathrm{C}$ targets. The U.S. National Academies of Sciences soon followed suit with its own "negative emissions technologies" (NETs) report (2019), vaunting NETs as an attractive commercial opportunity: "economic rewards" in the "international market" (see details in "Discussion" section below).

While legislative activity to support and incentivize commercial ICR (C-ICR) has advanced steadily, there has been almost no public dialogue about these methods (Anderson and Peters 2016; Dooley et al. 2018b; Pielke 2018; Adlen and Hepburn 2019). Nor has there been a policy-related examination of whether the methods reduce atmospheric carbon dioxide. As Adlen and Hepburn (2019) note, "Claims of ' $\mathrm{CO}_{2}$ avoided', ' $\mathrm{CO}_{2}$ removed' or 'reduced $\mathrm{CO}_{2}$ emissions' are easily confusable, and corporations and governments are starting to invest in various candidate technologies without having the big picture to hand."

In the meantime, a vast technical and scientific literature on carbon capture and storage has emerged (Martin et al 2017; Hayde and Semmler 2018; Minx et al. 2018; Morrow et al 2018). For our analysis, we reviewed over 200 scientific papers as well as journalistic reports. We also reviewed numerous bills and legislation. Our objective was to determine whether the carbon dioxide removal methods being publicly subsidized and incentivized are scientifically justified from the perspective of collective biophysical need. This is a novel approach. It joins public purpose with biophysical imperatives. That is, it combines the driving purpose of societal need (Colm 1936; Studenski 1939; Galbraith 1958; Wuyts 1992; Offe 2010; Sekera 2016, 2017; Chabbi et al. 2017) with the realities of biophysical constraints and imperatives that must be recognized by public policymakers. Together these two lenses form an over-arching criterion that we have termed "collective biophysical need." Given the fundamental problem around which there is general scientific consensus-excess atmospheric $\mathrm{CO}_{2}$-we define the collective biophysical need as a reduced level of atmospheric $\mathrm{CO}_{2}$. Within this over-arching criterion, we looked at three aspects of ICR. The first, and threshold, question is whether a given process removes more $\mathrm{CO}_{2}$ than it emits. We then looked at resource usage at climate-significant scale, (particularly energy consumption and land requirements); and ancillary biophysical impacts at scale. (For details, see "Methods" section).

This biophysical approach is in contrast to the perspective of commercial viability, which is widespread in both the scientific literature and in public policymaking on carbon dioxide removal. That approach rests on a market-centric perspective, which leads to a tendency to assess the utility of carbon removal methods from the standpoint of their commercial viability, and which assumes that commercial firms will be the source of climate mitigation solutions. We undertook our study as policy analysts who have found a biophysical approach essential to, but generally missing from, public policymaking.

\section{Terms, Abbreviations, Definitions}

Table 1 contains the definitions of the terms and abbreviations used in this article.

\section{Terminology Confusion in the Literature: CCS and CCUS}

In the literature, the "U" in CCUS is meant to indicate that the captured carbon is "utilized" for a product or a process. The absence of the "U" implies that the captured carbon is stored rather than being "utilized." In reality, the distinction between CCS and CCUS is meaningless: regardless of which term is applied, the captured carbon is predominantly used to produce oil (see "Discussion" section). The term "CCUS" was fabricated circa 2013 (Pigeon 2019) in order to highlight the potential commercial value of captured $\mathrm{CO}_{2}$; the U.S. Dept. of Energy then "re-branded" CCS to CCUS (Veld et al. 2013).

\section{Carbon Removal Methods Addressed in This Paper}

There are a variety of possible methods of engineered, mechanical and chemical methods of carbon dioxide removal. We focused on point-source capture and direct air capture because these methods have gained the most traction in terms of public policy and legislation, particularly in the U.S and the U.K. and among some EU policymakers. Thus, we do not address, for example, "enhanced weathering," "ocean fertilization," or Bioenergy with Carbon Capture and Storage (BECCS). The methods addressed in this paper are as follows:

- Point-source capture: Carbon Capture and Storage (CCS) and Carbon Capture Utilization and Storage (CCUS) Both 
Table 1 Terms used in the literature and in this paper

\begin{tabular}{|c|c|c|}
\hline Abbreviation & Term & Explanation \\
\hline CDR & Carbon dioxide removal & $\begin{array}{l}\text { Generally, as used in the literature, refers to all methods of carbon } \\
\text { capture and storage, including both mechanical-chemical methods and } \\
\text { biological methods. Does not include "geo-engineering"-interven- } \\
\text { tions, like solar radiation management (SRM), designed to limit the } \\
\text { amount of sunlight/energy reaching the planet's surface }\end{array}$ \\
\hline CCS & Carbon dioxide capture and storage & $\begin{array}{l}\text { Generally, in the literature, refers to capturing } \mathrm{CO}_{2} \text { from power plant flue } \\
\text { gas or from industrial manufacturing points of emissions, followed by } \\
\text { "utilization" and/or subsurface storage. Also referred to as "point- } \\
\text { source capture" }\end{array}$ \\
\hline CCUS & Carbon dioxide capture, utilization and storage & Emphasizes the goal of utilizing captured $\mathrm{CO}_{2}$ for commercial purposes \\
\hline CCS-EOR & Carbon capture and storage with enhanced oil recovery & $\begin{array}{l}\text { Enhanced Oil Recovery (EOR) using } \mathrm{CO}_{2} \text { captured from point-sources } \\
\text { or ambient air; contrasted with EOR using } \mathrm{CO}_{2} \text { obtained from natural } \\
\text { underground deposits of } \mathrm{CO}_{2}\end{array}$ \\
\hline DAC & Direct air capture & Capturing $\mathrm{CO}_{2}$ from ambient air \\
\hline ICR & Industrial carbon removal & $\begin{array}{l}\text { Mechanical-chemical methods, including both DAC and point-source } \\
\text { capture (CCS) }\end{array}$ \\
\hline C-ICR & Commercial ICR & $\begin{array}{l}\text { Commercial provision of mechanical-chemical carbon removal, as in the } \\
\text { case of pairing CCS or DAC with EOR }\end{array}$ \\
\hline- & Biological carbon sequestration & $\begin{array}{l}\text { Biological systems, e.g., photosynthesis and carbon sequestration in } \\
\text { biomass and soil }\end{array}$ \\
\hline
\end{tabular}

CCS and CCUS capture carbon dioxide at a point of emissions, such as a power plant or an industrial production site. The captured $\mathrm{CO}_{2}$ is either stored underground or used for commercial applications or both. Importantly, "pointsource" capture does not remove $\mathrm{CO}_{2}$ that is already in the atmosphere, and hence cannot, of itself, reduce the stock of atmospheric carbon dioxide. Its aim is to reduce new $\mathrm{CO}_{2}$ emissions. Capture can be pre-combustion, post-combustion, or via oxyfuel combustion, but those distinctions are not consequential in terms of the questions of interest in this study: whether the entire process adds to or reduces emissions, or reduces atmospheric $\mathrm{CO}_{2}$.

- Direct air capture (DAC) DAC pulls carbon dioxide from ambient air by mechanical means to draw in the air and uses chemical processes to separate out the $\mathrm{CO}_{2}$ for commercial use or storage.

\section{Biological Methods (Not Addressed in This Paper)}

Biological systems remove $\mathrm{CO}_{2}$ from the atmosphere and sequester it in soil and biomass. Such systems include forests (reforestation, afforestation, and averting deforestation); farming techniques (soil and biomass carbon sequestration through regenerative farming and other improved agricultural methods); grasslands and wetlands restoration. Our preliminary research suggests that biological methods are not only more effective at atmospheric $\mathrm{CO}_{2}$ reduction, they may also be more effective and efficient in resource usage not only in terms of energy but also in terms of land. In addition, they provide co-benefits such as soil-nutrient restoration, air and water filtration, fire management, and flood control. (See, e.g., Moomaw et al. 2019; Moomaw 2017; Bastin et al. 2019; Griscom et al. 2017; Fargione et al. 2018; Dooley et al. 2018; Lal 2018; Bai et al. 2019; Kane 2015; Rumpel et al. 2018; Smith et al. 2019; Wright 2017; Nature Conservancy 2016; Zomer et al. 2016; Zomer et al. 2017; Johnson (undated); Houghton and Nassikas 2018; Smith 2016). However, biological methods of carbon drawdown/sequestration are not the subject of this paper because it is mechanical-chemical methods that have gained the most legislative traction and public financial support. Further work is needed to compare mechanical-chemical and biological methods on a standardized basis - as discussed in the Conclusion.

\section{Methods}

We reviewed over 200 published studies, reports, and literature reviews on carbon dioxide removal and storage, most in scientific journals, as well as journalistic reporting. We also examined numerous public laws and bills. Our objective was to determine whether the carbon dioxide removal methods being publicly subsidized and incentivized are scientifically justified from the perspective of collective biophysical need, which, as discussed above, we defined as a reduction of atmospheric $\mathrm{CO}_{2}$. Within this over-arching criterion, we looked at three aspects of carbon capture and storage. The first, and threshold, question is whether a given process removes more $\mathrm{CO}_{2}$ than it emits, which we term impact on carbon balance. Next, we examined questions of energy consumption and land 


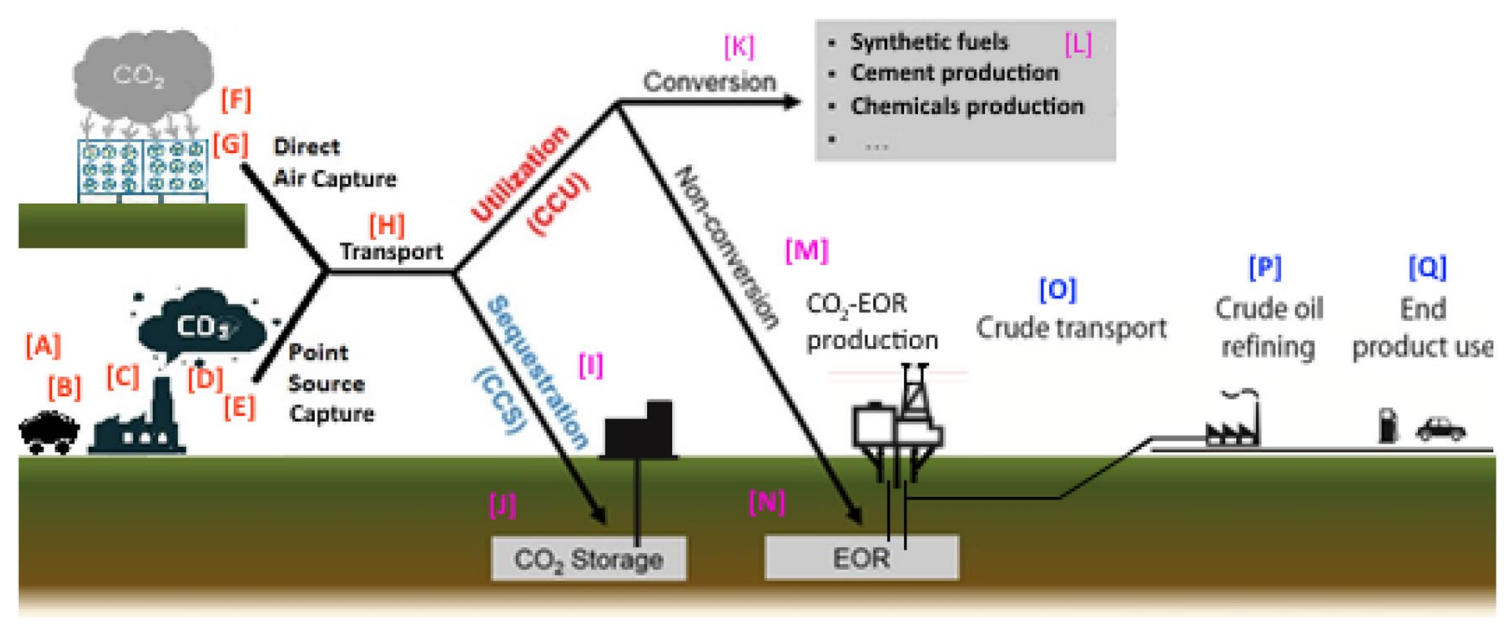

Fig. 1 Full life cycle. Pathways associated with industrial carbon removal (ICR). (Image elaborated from Wikipedia entry on carbon capture and utilization and from Stewart and Haszeldine 2014.)

requirements at climate-significant scale, because resource usage looms large both in carbon removal considerations and in terms of societal needs. Third, we looked at carbon removal methods in terms of their biophysical impacts, which have major implications for public policy choices about allocating limited physical, financial, and human resources.

\section{Approach to Assessing ICR Methods from the Perspective of Collective Biophysical Need}

Collective biophysical need: Reduction of atmospheric $\mathrm{CO}_{2}$

Each ICR method is examined in terms of:

Dimension (a) Impact on carbon balance

Dimension (b) Resource usage at scale

Dimension (c) Biophysical impacts, particularly at scale

Following are our methods for examining each dimension.

\section{Dimension (a): Impact on Carbon Balance}

Given the excess of atmospheric $\mathrm{CO}_{2}$, the collective biophysical need is to achieve an absolute reduction in the amount of atmospheric $\mathrm{CO}_{2}$. Thus, the threshold measure in our analysis is: Does the process sequester more $\mathrm{CO}_{2}$ than is emitted by the full process? This measure can be expressed as a ratio ${ }^{5}$ :

$\gamma_{\mathrm{CO}_{2}}=\frac{\text { Total } \mathrm{CO}_{2} \text { emitted }}{\text { Total } \mathrm{CO}_{2} \text { sequestered }}$

\footnotetext{
${ }_{5}$ Ratio suggested by Robert K. Kaufmann, Prof. of Earth and Environment, Boston University; meeting April 19, 2019.
}

where:

$\gamma_{\mathrm{CO}_{2}}=$ impact on carbon balance;

total $\mathrm{CO}_{2}$ emitted $=$ the amount of $\mathrm{CO}_{2}$ emitted by the entire process;

total $\mathrm{CO}_{2}$ sequestered $=$ the amount of $\mathrm{CO}_{2}$ sequestered by the entire process.

A ratio of $\gamma_{\mathrm{CO}_{2}}$ greater than 1 means that the process adds more $\mathrm{CO}_{2}$ to the atmosphere than it sequesters. It is net additive and would therefore not meet the collective biophysical need of atmospheric carbon dioxide reduction.

In order to assess whether a process adds to or reduces atmospheric $\mathrm{CO}_{2}$, and to calculate the above ratio, it is necessary to look at the entire capture and storage process, and to compare the total quantity of $\mathrm{CO}_{2}$ emissions with the quantity of $\mathrm{CO}_{2}$ removed and stored. This requires a full life cycle analysis (LCA).

Figure 1 is a diagram of industrial processes of $\mathrm{CO}_{2}$ sequestration, illustrating two methods of capture, one being direct air capture and the other being point-source capture (in this case a coal-fueled power plant equipped for $\mathrm{CO}_{2}$ capture). The diagram illustrates three possible types of disposition of the captured $\mathrm{CO}_{2}$ : dedicated storage in an underground geological formation (J); "storage" of the $\mathrm{CO}_{2}$ in other types of products such as synfuels or use of the $\mathrm{CO}_{2}$ in cement production $(\mathrm{L})$; storage in an underground oil reservoir after the use of the $\mathrm{CO}_{2}$ for EOR $(\mathrm{N})$.

The processes both emit and remove $\mathrm{CO}_{2}$. Flows $\mathrm{A}, \mathrm{B}$, $\mathrm{C}, \mathrm{E}, \mathrm{G}, \mathrm{H}, \mathrm{I}, \mathrm{K}, \mathrm{M}, \mathrm{O}, \mathrm{P}$, and $\mathrm{Q}$ add $\mathrm{CO}_{2}$ to the atmosphere. Flows $\mathrm{D}$ and $\mathrm{F}$ remove $\mathrm{CO} 2$ from the atmosphere, but also add $\mathrm{CO}_{2}$ to the atmosphere through the energy used to operate the process ( $\mathrm{E}$ and $\mathrm{G})$. Only flows $\mathrm{J}$ and $\mathrm{N}$ (storage) actually remove $\mathrm{CO}_{2}$ from the atmosphere for any significant period of time. Utilization, $\mathrm{L}$, stores $\mathrm{CO}_{2}$ for a limited amount of time (Table 2). 
Table 2 Legend for figure elements in Fig. 1

\begin{tabular}{|c|c|c|c|c|}
\hline Section & Sub-section & Emission sign & $\begin{array}{l}\text { Figure } \\
\text { ele- } \\
\text { ment }\end{array}$ & Explanation \\
\hline \multirow[t]{7}{*}{ (I) Carbon origin } & \multirow[t]{5}{*}{ (Ia) Point source capture plant } & $(+)$ & A & $\mathrm{CO}_{2}$ emitted to atmosphere from mining/processing coal \\
\hline & & $(+)$ & $\mathrm{B}$ & $\mathrm{CO}_{2}$ emitted to atmosphere from transporting coal \\
\hline & & $(+)$ & $\mathrm{C}$ & $\mathrm{CO}_{2}$ emitted to atmosphere from burning coal \\
\hline & & (C) & $\mathrm{D}$ & $\mathrm{CO}_{2}$ captured from flue gas by ICR (point-source capture) \\
\hline & & $(+)$ & $\mathrm{E}$ & $\mathrm{CO}_{2}$ emitted to atmosphere by ICR (point-source process) \\
\hline & \multirow[t]{3}{*}{ (Ib) Direct air capture plant } & (C) & $\mathrm{F}$ & $\mathrm{CO}_{2}$ captured from atmosphere by ICR (DAC) \\
\hline & & $(+)$ & G & $\mathrm{CO}_{2}$ emitted to atmosphere by ICR (DAC) \\
\hline (II) Transport & & $(+)$ & $\mathrm{H}$ & $\begin{array}{l}\mathrm{CO}_{2} \text { emitted to atmosphere by transport of } \mathrm{CO}_{2} \text { to injection } \\
\text { or utilization site }\end{array}$ \\
\hline \multirow[t]{9}{*}{ (III) Carbon disposition } & \multirow[t]{2}{*}{ (IIIa) Carbon sequestration } & $(+)$ & I & $\mathrm{CO}_{2}$ emitted to atmosphere by injection process \\
\hline & & $(\mathrm{S})$ & $\mathrm{J}$ & $\mathrm{CO}_{2}$ stored in geological formation \\
\hline & \multirow[t]{2}{*}{ (IIIb) Other carbon utilization } & $(+)$ & $\mathrm{K}$ & $\begin{array}{l}\mathrm{CO}_{2} \text { emitted to atmosphere in conversion for commercial } \\
\text { uses (other than EOR) }\end{array}$ \\
\hline & & $(\mathrm{S})$ & $\mathrm{L}$ & $\begin{array}{l}\mathrm{CO}_{2} \text { stored in products (but returns to atmosphere when } \\
\text { products are burned or decompose) }\end{array}$ \\
\hline & \multirow{5}{*}{$\begin{array}{l}\text { (IIIc) Carbon used for } \\
\text { Enhanced Oil Recovery } \\
\text { (EOR) }\end{array}$} & $(+)$ & M & $\begin{array}{l}\mathrm{CO}_{2} \text { emitted to atmosphere from oil production and multiple } \\
\text { cycling injections }\end{array}$ \\
\hline & & $(\mathrm{S})$ & $\mathrm{N}$ & $\mathrm{CO}_{2}$ remaining in underground oil reservoir \\
\hline & & $(+)$ & $\mathrm{O}$ & $\mathrm{CO}_{2}$ emitted to atmosphere from crude transport \\
\hline & & $(+)$ & $\mathrm{P}$ & $\mathrm{CO}_{2}$ emitted to atmosphere from crude oil refining \\
\hline & & $(+)$ & $\mathrm{Q}$ & $\mathrm{CO}_{2}$ emitted to atmosphere from oil combustion \\
\hline
\end{tabular}

Point-source capture and direct air capture have different objectives. The goal of the former is to reduce or avoid increases to the stock of atmospheric $\mathrm{CO}_{2}$ from fossil fuel combustion; the goal of the latter is to produce an absolute reduction in the existing stock of atmospheric $\mathrm{CO}_{2}$. Pointsource capture cannot reduce the stock of atmospheric $\mathrm{CO}_{2}$ since it cannot store more than it captures. The theoretical best it could accomplish is to prevent additional $\mathrm{CO}_{2}$ emissions from increasing the atmospheric stock (i.e., a ratio of emissions to amount stored of no greater than 1 ). If any process adds to the stock of $\mathrm{CO}_{2}$, it is counterproductive from the standpoint of collective biophysical need.

For point-source carbon removal to effectively prevent additional emissions, which we call achieving "net stasis," or for DAC to remove carbon from the atmosphere, which we call "net removal," the process must not release more carbon dioxide than the amount removed. In any analysis to determine the net amount of emissions vs removals, the "project boundaries" of that analysis must include all of the stages involved, including obtaining, processing, and transporting the fossil fuel (e.g., coal, natural gas) used in the power plant or manufacturing facility; capturing the $\mathrm{CO}_{2}$ from that "point-source," or, in the case of DAC, capturing from ambient air; transport to places of injection and storage or use; injection of $\mathrm{CO}_{2}$ into subsurface storage sites (and, in the case of EOR, recycling of used $\mathrm{CO}_{2}$ to return it back underground) or conversion for use in commercial products; and-in processes wherein the $\mathrm{CO}_{2}$ is "utilized" prior to or instead of storage-production of oil or other products and the emissions from end use. Figure 1 diagrams the full life cycle of point-source capture (in this example, the flue gas of a fossil-fueled plant; coal is used as the example) and direct air capture. In each stage of the process, $\mathrm{CO}_{2}$ is either generated or removed.

Conditions under which point-source capture could accomplish net stasis:

\section{Point source capture; dedicated storage}

The only way for the process to accomplish net stasis is if flow $\mathrm{J}$ is not less than the sum of flows $\mathrm{A}, \mathrm{B}, \mathrm{C}$, $\mathrm{E}, \mathrm{H}$, and $\mathrm{I}$.

Point source capture with EOR

The only way for the process to accomplish net stasis is if flow $\mathrm{N}$ is not less than the sum of flows $\mathrm{A}, \mathrm{B}, \mathrm{C}$, $\mathrm{E}, \mathrm{H}, \mathrm{M}, \mathrm{O}, \mathrm{P}$ and $\mathrm{Q}$.

Point source capture; other utilization

The only way for the process to accomplish net stasis is if flow $\mathrm{L}$ is not less than the sum of flows $\mathrm{A}, \mathrm{B}, \mathrm{C}$, $\mathrm{E}, \mathrm{H}$ and $\mathrm{K}$.

Conditions under which direct air capture could be a net remover of $\mathrm{CO}_{2}$ from the atmosphere: 
Direct air capture; dedicated storage

The only way the process could be a net remover of $\mathrm{CO}_{2}$ from the atmosphere is for flow $\mathbf{J}$ to be greater than the sum of flows $\mathrm{G}, \mathrm{H}$ and $\mathrm{I}$.

\section{Direct air capture with EOR}

The only way the process could be a net absolute remover of $\mathrm{CO}_{2}$ from the atmosphere is for flow $\mathrm{N}$ to be greater than the sum of flows $\mathrm{G}, \mathrm{H}, \mathrm{M}, \mathrm{O}, \mathrm{P}$ and Q. Direct air capture, other utilization

The only way the process could be a net absolute remover of $\mathrm{CO}_{2}$ from the atmosphere is for flow $\mathrm{L}$ to be greater than the sum of flows $\mathrm{G}, \mathrm{H}$ and $\mathrm{K}$.

In the "Results" section we examine the concepts and boundaries used in the studies we reviewed to determine whether they meet our standard for accomplishing "net stasis" or "net removal."

\section{Dimension (b): Resource Usage at Scale}

\section{Outcome Standardization}

Studies vary in their assumptions concerning resource inputs (like energy and land) which leads to differing projections for the achievable amount of output $\left(\mathrm{CO}_{2}\right.$ removal) a particular carbon removal method can achieve. The discrepant assumptions among studies create difficulty when trying to compare methods of removal on the quantity of resources required. For our study, we were interested in the amount of resources it takes various methods to achieve a specified level of output. Thus, our approach was to standardize for outcome. It is then possible to analyze studies of each method in terms of resource inputs.

\section{Scale}

Our objective was to compare ICR methods in their resource usage at a climate-significant level of $\mathrm{CO}_{2}$ reduction. Therefore, we chose the outcome level of $1 \mathrm{GtCO}_{2}$ removal per year-in order to compare the resource inputs required to achieve that level of output. We chose the $1 \mathrm{Gt}$ level because a number of studies examine resource needs at that level, and because $1 \mathrm{Gt}$ removal is minimal for any appreciable impact when considering the level of annual of annual $\mathrm{CO}_{2}$ emissions, approximately 37 Gt globally in 2019 and $5.1 \mathrm{Gt}$ in the U.S. in 2019 (U.S. Energy Information Association 2020).

Therefore, our research question was: At 1 Gt scale, how much energy is consumed by a process? How much land is required?

\section{Dimension (c): Biophysical Impacts, Particularly at Scale}

\section{Biophysical Analysis, Not Financial Analysis}

Our review examined methods of carbon dioxide removal in terms of foundational biophysical questions related to collective need. We did not analyze financial cost, because it is biophysical aspects that are neglected in public policymaking. In contrast, the majority of ICR studies approach scaling up as a financial problem. Scientific and technical reports on ICR frequently overlay a market framework on their biophysical or engineering analysis and then draw their conclusions about the viability of ICR methods. In such studies, commercial financial viability often supplants biophysical considerations.

Our research question was: What are the biophysical impacts of each method, particularly at scale?

\section{Results}

\section{Summary of Findings}

\section{Impact on Carbon Balance}

Neither of the two principal industrial carbon removal (ICR) methods being promoted and subsidized by governments meets the collective biophysical need of atmospheric $\mathrm{CO}_{2}$ reduction, and both are net $\mathrm{CO}_{2}$ additive as presently practiced. These are point-source capture in which the captured carbon is used for oil production, and direct air capture when wholly fossil fuel powered and all emissions produced by the process are accounted for. Point-source CCS cannot reduce atmospheric $\mathrm{CO}_{2}$, since it can never store more than it captures, and as currently practiced is also net additive (with only rare and minor exceptions where the captured $\mathrm{CO}_{2}$ is simply injected underground). Point-source CCS even at its theoretical best is somewhat net $\mathrm{CO}_{2}$ additive. (Indeed, CCS is not normally considered a "negative emissions technology.") DAC, when fossil fuel powered and the full process and emissions are accounted, is also net $\mathrm{CO}_{2}$ additive. That is, in both cases the processes add more $\mathrm{CO}_{2}$ to the atmosphere than they remove, emitting - in the case of point-source capture-from 1.42 to 4.7 tons of $\mathrm{CO}_{2}$ to the atmosphere for each ton removed (see Table 3 ) and-in the case of direct air capture-emitting from 1.46 to 3.44 tons of $\mathrm{CO}_{2}$ for each ton removed. ${ }^{6}$ Nevertheless, as explained in the "Discussion" section, some studies, through their methodological choices, report point-source capture and direct air

\footnotetext{
$\overline{6}$ See Table 3 for calculations source.
} 


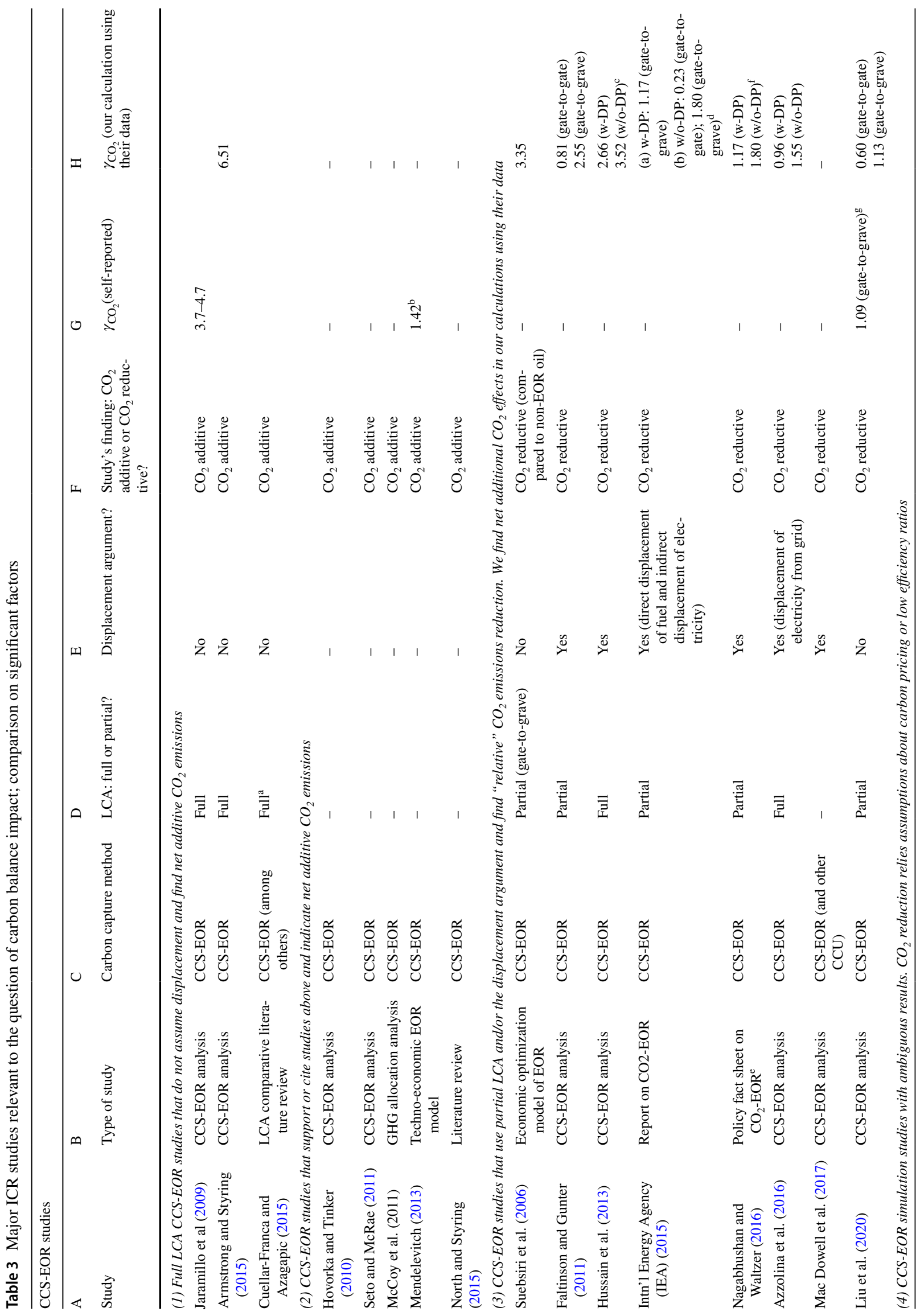




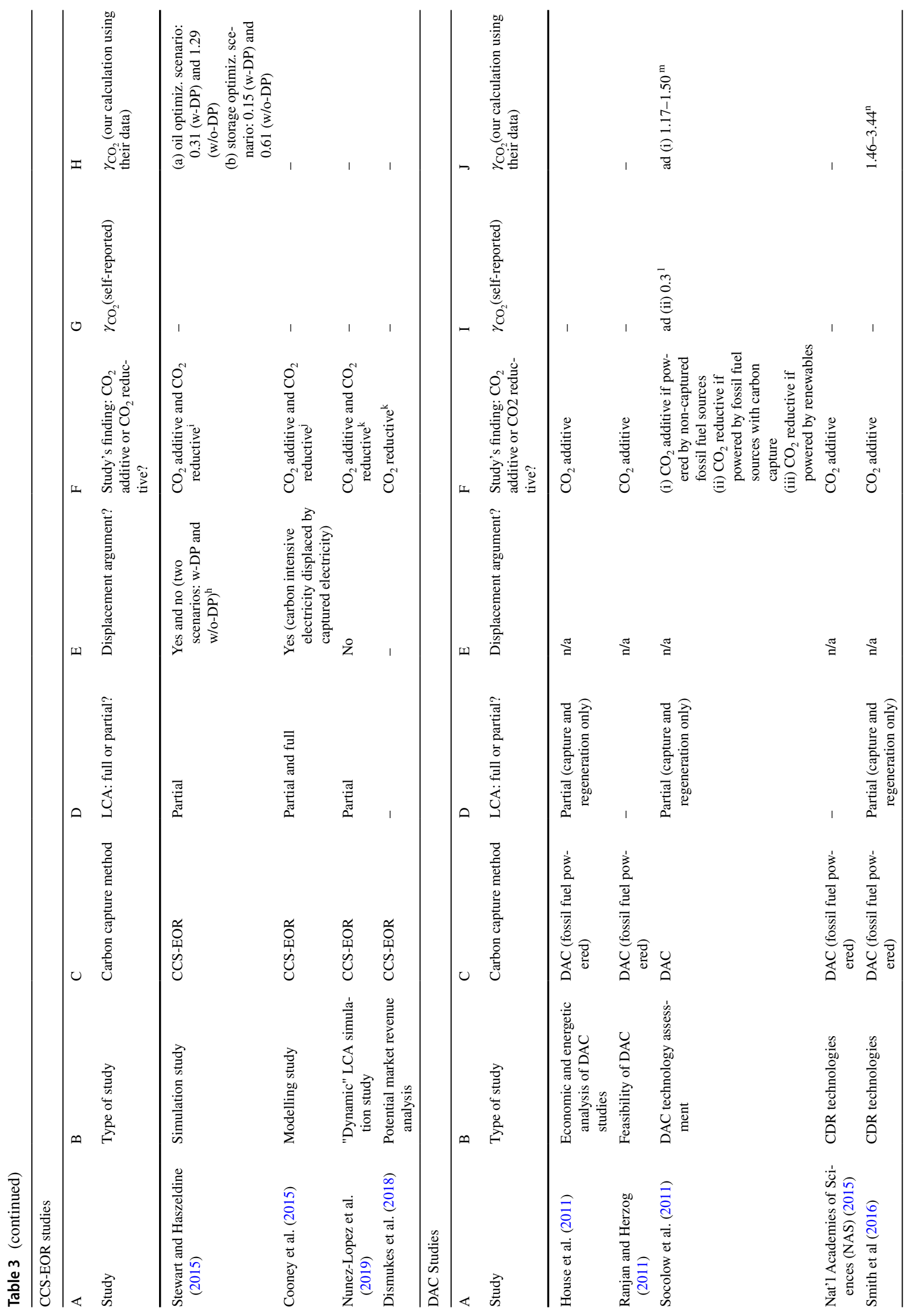




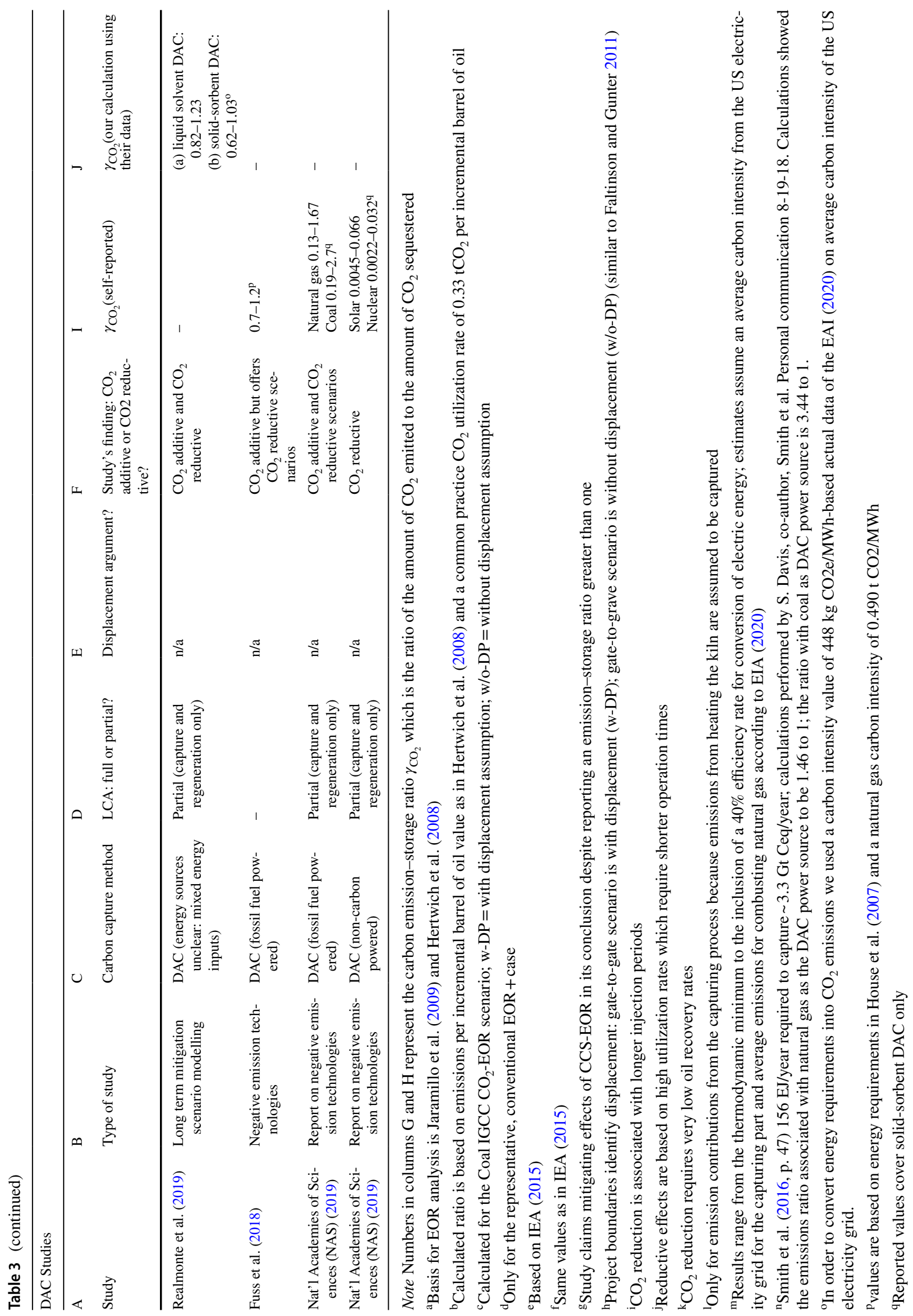


capture to be climate mitigating or net $\mathrm{CO}_{2}$ reductive-by leaving out part of the life cycle process, by assuming lowor zero-carbon power sources, by invoking an emissionsdiscounting "displacement" assumption or by ignoring that, in real-world practice, captured $\mathrm{CO}_{2}$ is primarily used for oil production.

Captured $\mathrm{CO}_{2}$ is primarily used for oil production"enhanced oil recovery" (EOR) in which $\mathrm{CO}_{2}$ is injected into partially depleted oil reservoirs to extract residual oil. In the United States, which is the world leader in CCS, virtually the only use of the captured carbon is EOR (Foehringer Merchant 2018). EOR is also the primary use of captured $\mathrm{CO}_{2}$ globally-the vast majority of captured $\mathrm{CO}_{2}$ that has been injected for subterranean storage worldwide was first used for oil extraction via EOR (Global CCS Institute 2018). An analysis of the "Facility Data" on the Global Carbon Capture Institute website also indicates that most captured $\mathrm{CO}_{2}$ is used for EOR. ${ }^{7}$ As Dismukes et al (2018) stress: "The use of EOR changes the nature of carbon from being a pollutant to a valuable commercial input..." EOR is the predominant use of $\mathrm{CO}_{2}$ not only in point-source capture, but also is emerging as the predominant use in DAC (Blum 2019; Storrow 2020), something that is not generally acknowledged in the technical literature on DAC.

Scientific and technical papers commonly argue that captured $\mathrm{CO}_{2}$ could be "utilized" for a variety of products other than oil, including synfuels, chemicals, building materials, and cement (e.g., Sandalow et al. 2017; Davis et al. 2018; Soltoff 2019; Hepburn et al. 2019). However, there is no climate-significant level of alternative demand for captured $\mathrm{CO}_{2}$ at this time or in the foreseeable future because utilization volumes fall far short of sequestration need (Bennett et al. 2014; Schäfer et al. 2015; Mac Dowell et al. 2017; Foehringer Merchant 2018; Center for International Environmental Law 2019; van Renssen 2020; Global CCS Institute, undated) and most of these uses would result in the $\mathrm{CO}_{2}$ soon being recycled back into the atmosphere. For details see Online Appendix 1.

In principle, it may be possible for $\mathrm{DAC}$ to be net $\mathrm{CO}_{2}$ reductive if powered by a non-carbon energy source and if the captured carbon is stored underground and not used for commercial production. Operationally there are only extremely small-scale pilots (e.g., Climeworks experiments in Switzerland and Iceland). We found no analyses of a fullscale, renewables-powered DAC process based on a full life cycle (see Fig. 1) and including embodied emissions and emissions from chemicals (e.g., sorbent) manufacture. Yet,

\footnotetext{
7 https://co2re.co/FacilityData Concerning the usage of $\mathrm{CO}_{2}$ from the CCS projects, filtering the data for largescale CCS projects-almost every project in the list indicates that captured $\mathrm{CO}_{2}$ is, or will be, used for EOR (data retrieved 05-30-20)
}

the major, but generally ignored, policy issue about subsidizing renewables-powered DAC is whether renewable energy should be channeled for carbon removal rather than used directly to reduce carbon emissions by powering homes, industry, businesses, and transport.

\section{Resource Usage at Scale}

As explained in the "Methods" section, our approach in reviewing resource requirements for ICR processes was to look at a standardized output in order to compare resource input requirements on a common basis. The output amount we standardized for is $1 \mathrm{GtCO}_{2}$ removal per year. We examined energy and land requirements at that level of capture. We found that the literature regularly discusses the massive energy usage of DAC. For example, just $1 \mathrm{Gt}$ removal could consume a quantity of energy approaching the total electricity generation for the US in 2017. But much of the literature neglects to point out that even the large amounts of energy estimated regularly omit many downstream stages of the DAC life cycle process. While renewables-powered DAC may be net $\mathrm{CO}_{2}$ reductive, according to one estimate, renewables-powered DAC would require all of the wind and solar energy generated in the U.S. in 2018 to capture just 1/10th of a Gt of $\mathrm{CO}_{2}$. Details are below.

In terms of land requirements, we found that the literature on ICR — both point-source capture and DAC - regularly slights, and sometimes ignores, the land requirements for ICR. At-scale land requirements for pipelines are little addressed. One researcher explains that at the scale of 1 $\mathrm{Gt}$ removal, the volume of $\mathrm{CO}_{2}$ would require a pipeline infrastructure that exceeds the current global oil handling infrastructure. While the literature occasionally discusses pipelines in relation to point-source capture, DAC land requirements, particularly at scale, are rarely addressed. DAC is normally vaunted as requiring little land, but a careful reading of some studies reveal its massive land requirements at scale. For example, data in the National Academies of Sciences NET report (2019) indicate that to remove 1Gt of $\mathrm{CO}_{2}$ using solar-powered DAC would require a land area ten (10) times the size of the state of Delaware. And this does not count the land required for pipeline transport, injection, and storage after the $\mathrm{CO}_{2}$ has been captured. Socolow et al. (2011) did mention DAC land requirements, mentioning that, for DAC capture alone, a 30-km (19 miles)-long "direct air capture" structure would be needed just to balance out the $\mathrm{CO}_{2}$ emitted from a single 1000-MW coal-fired power plant. It is often said that DAC can be sited "anywhere," but that claim both ignores real-world barriers such as community acceptance and land acquisition constraints, and also disregards the inevitable lack of correspondence between sites where massive capture facilities might be situated, on the one hand, and suitable (safe and permanent) 
subsurface storage locations on the other. The question of subsurface storage space is commonly addressed, but there is extremely wide variance in estimates of "theoretical" vs "practical" geological storage capacity, as well as issues of permanence and safety. Details are below.

In terms of other resources, there is little information in the literature on other resource usage at scale. However, Realmonte et al. (2019) address sorbent production for DAC at scale, which would entail: "a massive deployment" and "major refocusing of the manufacturing and chemical industries for sorbent production, and a large need for electricity and heat." Details are below.

\section{Operating at Scale-Other Biophysical Issues and Impacts}

While we set out originally to look at potential biophysical impacts of operating ICR at scale, we found a host of other scale issues as well. The urgency of addressing scale issues is not reflected in science or policy (Minx et.al. 2018). Most studies that address the scaling-up challenge frame it as a financial problem. Only a few papers address biophysical and infrastructural issues of scaling up to a climate-significant level. There are multiple issues. The first is that the scale of ICR at this time is negligible. The amount of $\mathrm{CO}_{2}$ being captured and stored through CCS and DAC currently is inconsequential in relation to the excess concentration of $\mathrm{CO}_{2}$ in the atmosphere and in comparison to projected need. For example, the largest DAC facility globally captures only $4000 \mathrm{tCO}_{2}$ /year (Peters 2019; Soltoff 2019), which is only $0.000004 \mathrm{Gt}$. One unbuilt DAC facility aspires to capture $36,500 \mathrm{tCO}_{2}$ /year (Malo 2019), which is negligible: only $0.0000365 \mathrm{Gt}$, and another aspires to one million tons per year (Geman 2020), which is still only one one-thousandth of a Gt. Projections vary concerning the annual global sequestration rate needed; one study estimates $2.5 \mathrm{GtCO}_{2}$ per year by 2030, increasing to 8 to $10 \mathrm{Gt}$ per year by 2050 . Resource usage at scale — energy and land in particular-is another issue, summarized above and discussed more fully in "Resource Usage" section. Third is the matter of biophysical impacts at scale. These impacts include potential groundwater contamination, earthquakes caused by vast volumes of $\mathrm{CO}_{2}$ stored underground; "fugitive emissions" that pollute the air. Details are discussed in "Scale Issues" section . Fourth, a massive mobilization and diversion of material, human, and energy resources-which some have called a "wartime level of effort"- would be needed. Fifth is the matter of monitoring biophysical impacts and repercussions of transport and storage of massive amounts of captured $\mathrm{CO}_{2}$. An extensive monitoring, measuring, verification, and data tracking system would be required to verify storage and to detect and monitor leakage, air and water quality, seismic activity, and other ancillary impacts from subsurface storage. The sensing and tracking technology and network could constitute a new "Internet of Carbon" (Buck 2018), which, itself, raises questions of additional energy consumption and resulting additional $\mathrm{CO}_{2}$ emissions, land requirements, and intellectual property (IP) rights to such technology. Legislation would be required to establish standards for a monitoring system. Diligent, long-term monitoring and government-funded oversight would be needed, as experience thus far demonstrates that industry self-monitoring and reporting cannot be relied upon. In 2018, Clean Water Action reviewed industry claims for the $45 \mathrm{Q}$ carbon capture tax credit and found major discrepancies in industry reporting about how much $\mathrm{CO}_{2}$ was actually stored. Companies reported one amount to the IRS - nearly 60 million tonsto obtain their tax credits and another amount to EPA-3 million tons-to certify that they had permanently sequestered and stored the $\mathrm{CO}_{2}$. In 2020, a federal investigation prompted by Sen. Robert Menendez found that claimants for the 45Q tax credit failed to document successful geological storage for nearly $\$ 900$ million of the $\$ 1$ billion they had claimed (Frazin 2020; Hulac 2020). If ICR were operated at scale, these findings indicate that a monitoring and data tracking system may need to be government-operated.

In sum, the ICR effort globally is miniscule in relation to the scale of the problem. For DAC to operate at climatesignificant scale, the amount of energy required is massive and vast amounts of land are required. There are no plans presently for a pathway for addressing resource needs or for scaling up operations to a scale that would make any practical difference to the problem of excess atmospheric $\mathrm{CO}_{2}$. Moreover, most of the literature, and all of the evident policymaking dialogue, on ICR ignore the biophysical impacts of operating an ICR process at a climate-significant scale. These include emissions from material and infrastructure supply and the biophysical impacts from the $\mathrm{CO}_{2}$ removal process and from transport, injection, and storage at scale.

\section{Policy Implications}

Our chief policy finding is that there is no biophysical basis for governments to incentivize or subsidize current commercial ICR because there exists no operational, commercial process that results in net carbon removal. Moreover, no public subsidy of point-source capture is justified based on the polluter pays principle, a long-standing tenet in environmental law. Since dedicated storage, not sale, of captured $\mathrm{CO}_{2}$ is the only assured way that mechanical-chemical methods could meet the collective biophysical need of absolute atmospheric $\mathrm{CO}_{2}$ reduction, governments should approach $\mathrm{CO}_{2}$ removal and storage as a public service, like water treatment or waste disposal. It should be operated in the public interest, with $\mathrm{CO}_{2}$ captured from the air being sequestered for dedicated, permanent storage. Any legislation should be designed accordingly. Further, the biophysical scale issues 
associated with this process have been essentially unaddressed. Thus, prior to acting, policymakers must address the biophysical issues of operating mechanical-chemical carbon removal at climate-significant scale. Based on the evidence from our study, the question for policymakers is whether industrial carbon removal is a realistic option and, therefore, whether it should even be part of the policy mix.

\section{Discussion}

We found that most of the studies of ICR do not address our investigative, public policy-related, interests: carbon balance impact; resource usage at scale; and biophysical impacts at scale. Of the more than 200 papers and reports we reviewed, only about thirty directly address these issues. See Table 3.

\section{Impact on Carbon Balance}

In order for a carbon dioxide removal process to achieve either net stasis (prevent new fossil fuel emissions from adding to the stock of atmospheric $\mathrm{CO}_{2}$ ) or net removal (reduce the stock of atmospheric $\mathrm{CO}_{2}$ ), the emissions to storage ratio $\gamma_{\mathrm{CO}_{2}}$ of the process must be no greater than 1 for the former and below 1 for the latter. Reports on carbon dioxide removal and storage that do not include full life cycle emissions (Fig. 1) or that invoke a "displacement" assumption (discussed below) do not present a complete portrayal of the processes' emissions. In order to make a valid statement about the usefulness or benefit of a process in terms of collective biophysical need, all emission flows must be accounted for in the evaluation of that process. We found that papers that deem CCS-EOR to be a climate mitigation technique either fail to account for all emissions (i.e., they perform only a partial life cycle analysis) and/or they make an assumption that CCS-EOR-produced oil "displaces" conventionally produced fossil fuel energy. In either case the claim is that the CCS-EOR process produces not a net reduction but only a relative reduction in $\mathrm{CO}_{2}$ emissions compared to conventional fossil fuel energy production. In short, these papers claim that the process reduces $\mathrm{CO}_{2}$ emissions compared to business-as-usual (shown as " $\mathrm{CO}_{2}$ reductive" in Table 3), but the data show that the process actually results in net emissions. Similarly, papers that deem direct air capture to represent mitigation do not meet our criteria for "net removal," either because a full LCA has not been performed, or an assumption is made that DAC will be powered by renewable energy, which, itself, brings up a host of issues discussed herein but not addressed in most analyses.

\section{Studies That Meet Our Criteria}

A frequently cited full LCA study that meets our full LCA standard (Fig. 1) is by Jaramillo et al. (2009). This study found that "between 3.7 and 4.7 metric tons of $\mathrm{CO}_{2}$ are emitted for every metric ton of $\mathrm{CO}_{2}$ injected" underground (i.e., $\gamma_{\mathrm{CO}_{2}}=$ 3.7 to 4.7). Other papers that also find the process to be net $\mathrm{CO}_{2}$ additive, or that support or refer to the findings of Jaramillo et al., are as follows: Hovorka and Tinker (2010), Seto and McRae (2011), McCoy (2011), North and Styring (2015), Cuellar-Franca and Azagapic (2015), and Armstrong and Styring (2015), see Table 3. We did not find any paper that disagreed with the results of Jaramillo et al. (2009). Interestingly, even a promotional report advocating CCS-EOR (ScottMadden 2018) acknowledges that the CCS process at the largest CCS power plant project in the U.S. (Petra Nova) is net $\mathrm{CO}_{2}$ additive: "the total impact of the carbon capture system is actually an estimated $2 \%$ increase in $\mathrm{CO}_{2}$ emissions." Also see Mendelevitch (2013) and International Energy Agency (2015) both of which document how carbon accounting schema determine whether the process is found to be $\mathrm{CO}_{2}$ positive or negative.

Note When $\mathrm{CO}_{2}$ is captured directly from the emissions source and is simply injected into subsurface storage-with no EOR - the process might avoid being net additive. However, even without EOR, CCS is thermodynamically inferior to renewable energy production-Sgouris et al. (2019) found "[R]enewable technologies generally provide a better energetic return than CCS."

\section{Why the Papers That Do Not Meet Our Criteria Fail}

Some studies, and many meta-analysis reports on those studies, deem CCS-EOR ${ }^{8}$ to be a climate mitigation method. Following are the techniques and assumptions-which differ between point-source capture studies and direct air capture studies - that are employed in making this claim.

\section{Point-source studies}

(1) Perform only a partial life cycle analysis, omitting the $\mathrm{CO}_{2}$ released from the energy used during upstream and/or downstream stages of the process; and/or

(2) Invoke an unsupported assumption about energy production "displacement" based on theoretical "demand" theory in economics; and

(3) After having performed a partial LCA or invoked the "displacement" assumption, then present a model that

\footnotetext{
$\overline{8}$ The term CCS-EOR is used in this paper to mean $\mathrm{CO}_{2}$-EOR. Other substances, such as water, can also be used for EOR, sometimes in addition to $\mathrm{CO}_{2}$, but these other methods are not relevant to this paper.
} 
shows "reduced" $\mathrm{CO}_{2}$ emissions relative to conventional oil production, thereby representing climate "mitigation" or "abatement."

\section{DAC studies}

(1) Perform only a partial life cycle analysis; and or

(2) Make an assumption that DAC will be powered by renewable energy sources, ignoring the quantity of energy required to capture and sequester a climatesignificant amount of $\mathrm{CO}_{2}$, and ignoring the question of whether a society would decide to use the bulk of its renewable energy for DAC as opposed to using it for directly reducing emissions by powering buildings, transport, etc.

Following is a detailed discussion of each technique.

Partial LCA Studies that deem CCS-EOR to represent climate mitigation commonly perform a partial life cycle analysis, drawing a "project boundary" that omits parts of the full life cycle-either upstream or downstream emissions or both (see Fig. 2). The choice of boundary is especially important because captured $\mathrm{CO}_{2}$ is primarily used for enhanced oil recovery, and studies that perform a partial LCA often ignore downstream emissions from that use $(\mathrm{O}$, P, and Q in Fig. 2). Faltinson and Gunter (2011) advocate a partial LCA, arguing that $\mathrm{CO}_{2}$-EOR should "not include downstream emissions common to all sources of oil supply." Researchers define their boundaries differently depending on their research objectives. In some cases, the objective is, in fact, to support "oil production" goals (e.g., Nunez-Lopez et al. 2019). In some studies, the boundary begins at the point that $\mathrm{CO}_{2}$ is purchased, thereby ignoring the emissions from capturing the $\mathrm{CO}_{2}$ at the power plant or other source, and the emissions from transport of the $\mathrm{CO}_{2}$ to the oil well injection site (orange box in Fig. 2), and ends at the completion of the $\mathrm{CO}_{2}$-EOR injection process ( $\mathrm{M}$ in Fig. 2).

Studies that omit the upstream stage of $\mathrm{CO}_{2}$ sourcing fail to account for the additional $\mathrm{CO}_{2}$ emissions from the energy used to power the capture equipment itself. This is called the "energy penalty" or "efficiency penalty," and has been estimated at from 10 to $40 \%$ (Vasudevan et al. 2016; Oil Change International 2017). (A principal at Global Thermostat claims that their method reduces or eliminates the penalty by using residual heat to power the capture machinery; Chichilnisky 2019).

Omitting emissions from $\mathrm{CO}_{2}$ sourcing and/or from the combustion by consumers of $\mathrm{CO}_{2}$-EOR-produced oil can produce findings that the process is net $\mathrm{CO}_{2}$ negative. Many studies omit upstream or downstream or both, including Suebsiri (2006), Hertwich et al. (2008; as described in Cuellar-Franca and Azapagic 2015), Faltinson and Gunter
(2011), Wong (2013), International Energy Agency (2015), Lacy et al. (2015), Stewart and Haszeldine (2015), NunezLopez et al. (2019), portions of Nunez-Lopez and Moskal (2019), and Liu et al. (2020).

Some studies that omit a significant stage of the $\mathrm{CO}_{2}$-EOR process simply assert that the process represents "climate change mitigation." An example is a paper by Liu et al. (2020), which reports net $\mathrm{CO}_{2}$ emissions of producing one metric ton of crude oil as being negative: $-1675.15 \mathrm{~kg}$ $\mathrm{CO}_{2}$ (which yields a $\gamma_{\mathrm{CO}_{2}}$ value of 0.6 ). This result relies on the fact that they only account for gate-to-gate emissions of the $\mathrm{CO}_{2}$-EOR process. Yet the $\gamma_{\mathrm{CO}_{2}}$ value becomes positive (i.e., $\gamma_{\mathrm{CO}_{2}}$ value of 1.12) when the life cycle is extended and downstream emissions are included. A basic flaw of the paper-for public policy purposes-is that the analysis omits the upstream emissions from fuel-sourcing and energy usage for $\mathrm{CO}_{2}$ capture at the producer source from which the anthropogenic $\mathrm{CO}_{2}$ was obtained. This is a significant omission; such upstream segments of the CCS process may account for $25 \%$ to $32 \%$ of the total LCA emissions (Jaramillo et al. 2009; Hussain et al. 2013).

Other studies that use a partial LCA assert that the $\mathrm{CO}_{2}$-EOR process produces relative reductions, arguing that the emissions from this process are less than emissions from conventional oil production. This does not meet our standard of performing a straightforward analysis using the full life cycle. This is particularly so because most of the papers that make the argument about relative emissions also rely on the displacement assumption, discussed next. Another way to express concepts of reduction is in terms of stock and flow. An absolute reduction in the total stock of atmospheric carbon is distinct from a relative reduction of the continuously generated anthropogenic carbon flows. The latter will not necessarily result in absolute reduction. Many scientific papers look at relative flow reduction but not stock reduction. What is required is not simply a reduction "relative to" another industrial process, but rather a net absolute removal of $\mathrm{CO}_{2}$. "Absolute" as a measure of carbon removal effectiveness is often obscured and supplanted by notions "net zero" (see Allwood et al. 2019 on "Absolute Zero.").

A few studies point out the crucial, determinative significance of project boundary choices. One is by the International Energy Agency (2015). Another is Cuellar-Franca and Azapagic (2015) who refer to the studies of Jaramillo et al. (2009) and Hertwich et al. (2008) and note that only the former includes emissions from refining and combusting the oil extracted via EOR.

For public policy purposes, only studies that perform a full LCA are relevant. Although a partial LCA may suffice for investors interested in profit maximization, it is not of use for policymakers who want to address the collective biophysical need of absolute atmospheric $\mathrm{CO}_{2}$ reduction. 


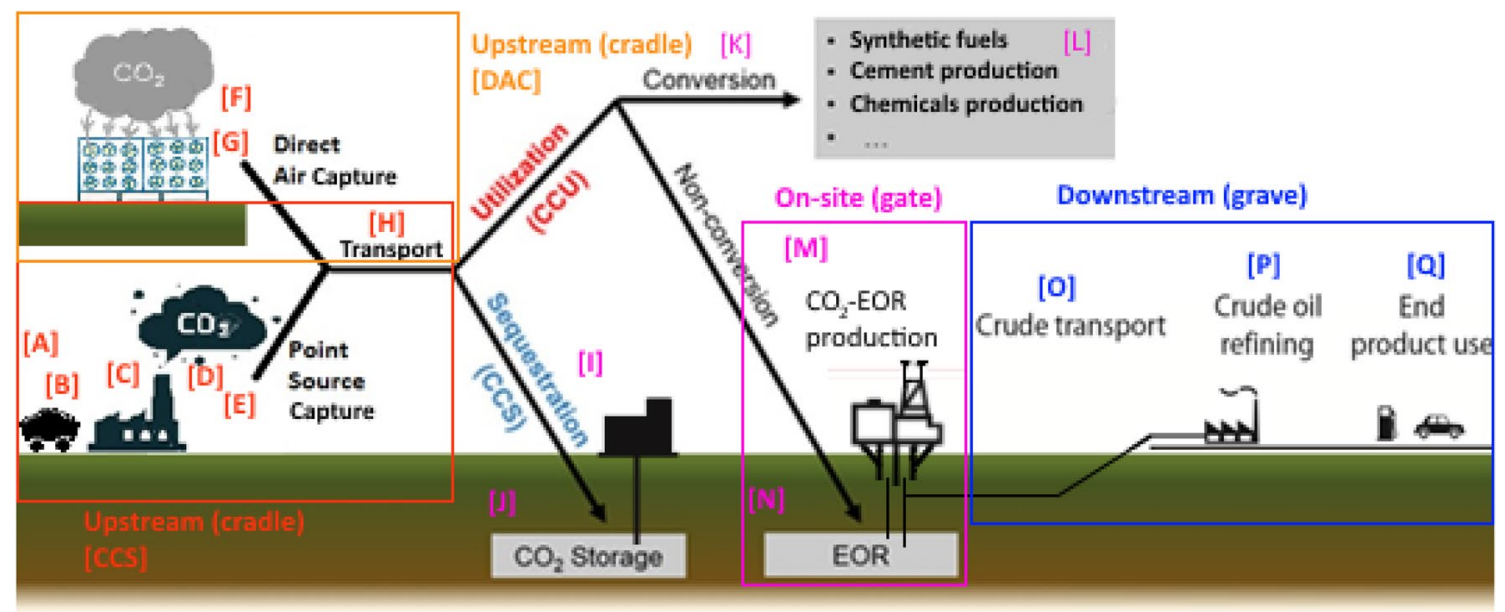

Fig. 2 Full life cycle components. Upstream, on-site, and downstream operations. (Image elaborated from Wikipedia entry on carbon capture and utilization and from Stewart and Haszeldine 2014.)

Table 3 displays information on ICR papers pertaining to our research metric of carbon balance impact. Columns $\mathrm{D}$ and $\mathrm{E}$ indicate whether the study used a full or partial LCA and whether it assumed displacement; column F shows the paper's conclusion about whether the process represents "mitigation"; and column G shows the ratio of emissions to removals in the instances where this was reported in the study. Where the data were available, we used the data in the papers to calculate the ratio of emissions to removals overall, and without the displacement assumption (column $\mathrm{H}$ ).

The "Displacement" Assumption Some studies report that CCS-EOR represents climate change "mitigation" or "abatement" by making an assumption about energy production "displacement." In the "displacement" assumption, it is asserted that the CCS-EOR-produced oil displaces a certain amount of conventionally produced oil. EOR oil is said to have lower $\mathrm{CO}_{2}$ emissions than conventionally produced oil (because some of the $\mathrm{CO}_{2}$ remains underground), and, using the assumption that the EOR oil displaces conventionally produced oil, authors are able to assert that a relative $\mathrm{CO}_{2}$ emissions reduction takes place. In the literature, we found that the way the displacement argument unfolds is either by constricting the carbon accounting framework to a partial LCA (i.e., cutting off the downstream part as in Faltinson and Gunter 2011) and thereby ignoring those emissions, or by treating the difference of emissions between conventional and non-conventional oil as an amount that can be further deducted (e.g., in International Energy Agency 2015). In some studies, the displacement factor is not "credited" to conventional barrels of oil but to electricity generation at the point where the $\mathrm{CO}_{2}$ was sourced (e.g., Azzolina et al. 2016). In effect, even though the overall CCS-EOR process is net $\mathrm{CO}_{2}$ additive (releases more $\mathrm{CO}_{2}$ than it sequesters) it is claimed that the EOR-produced oil results in "net reductions" (International Energy Agency 2015). Such a perspective frames "net reductive" not in the way of absolute reduction but in the sense of releasing fewer emissions than oil produced in the business as usual scenario. That theoretical, comparative, "reduction" in emissions is labeled "mitigation." The displacement argument is primarily made in studies of CCS-EOR, but would also apply to DAC-EOR.

The displacement argument was laid out a decade ago by Faltinson and Gunter (2011): "World oil production is determined by world oil demand and if $\mathrm{CO}_{2}$-EOR projects were not undertaken, some other source of oil would step forward and fill the gap." That paper, using the displacement assumption and a partial LCA concludes that: "executing $\mathrm{CO}_{2}$-EOR projects will not result in incremental aggregate refining and consumption emissions." That would yield a mean $\gamma_{\mathrm{CO}_{2}}$ of 0.81 (a CO $\mathrm{CO}_{2}$ reduction). However, we used their data, which includes downstream emissions (though not upstream emissions) and found that the overall carbon emission-storage ratio becomes 2.55 (the process is a net $\mathrm{CO}_{2}$ emitter). Numerous studies invoke the displacement assumption including Hussain et al. (2013, pp. 132, 134), Wong et al. (2013), Cooney et al. (2015), International Energy Agency (2015), Azzolina (2016), Nagabhushan and Walzer (2016), Nunez-Lopez and Moskal (2019), and Nagabhushan and Thompson (2019) (see Table 3). Choosing to invoke this assertion is determinative: when it is used it "results in net negative emissions from $\mathrm{CO}_{2}$-EOR," whereas assuming that the oil produced by $\mathrm{CO}_{2}$-EOR is additional oil "results in $\mathrm{CO} 2-\mathrm{EOR}$ with net positive emissions" (Kolster et al. 2017). The "displacement" argument is further complicated by choice of "efficiency factor," which affects the amount of displacement that is calculated. For details, see Online Appendix 2. 
Evidence to support the displacement assertion is lacking. The assertion has been questioned or challenged by a number of researchers. E.g., Mac Dowell (2017) and Jaramillo et al. (2009) who conclude: "A thorough understanding of ultimate displacement is necessary before anyone can suggest that $\mathrm{CO}_{2}$-EOR is a sequestration technique... It is clear, that without displacement of a carbon intensive energy source $\mathrm{CO}_{2}$-EOR systems will result in net carbon emissions." (Emphasis added.) Veld et al. (2013) also challenge the displacement assumption, arguing that $\mathrm{CO}_{2}-\mathrm{EOR}$ "may not displace any conventional production at all..." In fact, the U.S. Department of Energy (2016) itself has made the argument that CCS-EOR will add to U.S. oil production, stating that: " $\mathrm{CO}_{2}$-EOR has the important co-benefit of increasing domestic oil production..." A report by the Center for International Environmental Law (2019, p. 17) also rebuts the displacement argument.

Besides the lack of empirical evidence, the displacement assumption is founded on a conceptual flaw. It confuses need for energy with "demand for oil." The displacement assumption relies on an idea of fossil fuel "demand" which derives from market economics teaching. The concept of "demand" is an artifact of market economics theory, and its unsuitable use in carbon removal modeling fails to recognize the difference between need and demand. In contrast to theoretical, modeled "demand" is societal need, (Wuyts 1992; Hodgson 2013; Goodwin et al 2014; Desmarais-Tremblay 2017) which is the collective expression of individual human wants. Societies need energy; they do not necessarily need the source to be a fossil fuel. Moreover, oil demand is a variable whose level can be increased or decreased by various factors, including demand reduction through public policy. Numbers of countries, states, and cities are actively reducing fossil fuel demand through policy and legislation (Wettengel 2019; Baker 2020) as they move their societies and economies to other ways of meeting their energy need.

Modeling Assumptions and Methodological Choices As can be seen from the foregoing discussion, and as pointed out in some ICR studies (Mendelevitch 2013; Wong et al 2013; Stewart and Haszeldine 2014; Boot-Hanford 2014; International Energy Agency 2015; Kolster et al 2017), differing modeling assumptions, project boundaries, and methodological choices affect conclusions. Each study, in effect, creates its own $\mathrm{CO}_{2}$ "accounting framework" (McCormick 2012). By using a partial life cycle analysis or the "displacement" assumption some studies deem commercial ICR methods to achieve "climate mitigation," "abatement," or "decarbonization" (International Energy Agency 2015; Azzolina et al 2016; Nagabhushan and Waltzer 2016; Realmonte et al 2019; IPCC 2018; Nunez-Lopez et al 2019; Nunez-Lopez and Moskal 2019; Nagabhushan and Thompson 2019; Liu et al., 2020). Such conclusions generally rely upon an argument that reducing $\mathrm{CO}_{2}$ emissions relative to existing or theoretical emissions amounts to mitigation (e.g., Faltinson and Gunter 2011; Godec et al. 2013; Cooney et al. 2015; International Energy Agency 2015; Azzolina et al. 2016; Nagabhushan and Waltzer 2016; Nunez-Lopez et al. 2019). A few others find that the process alternates between being net $\mathrm{CO}_{2}$ negative and net positive. Yet, none of these studies address the ultimate question of net impact on the "stock" of atmospheric $\mathrm{CO}_{2}$. In contrast, other analyses find that, in these same processes, $\mathrm{CO}_{2}$ emissions exceed removals (e.g., Jaramillo et al. 2009; Armstrong and Styring 2015; Cuellar-Franca and Azagapic 2015; Smith et al. 2016) or refer to those findings (e.g., Hovorka and Tinker 2010; Seto and McRae 2011; McCoy 2011; North and Styring 2015; International Energy Agency 2015)

Market Framing: The Commodification of $\mathrm{CO}_{2}$ in Carbon Removal Research The U.S. Supreme Court ruled in 2007 and 2014 that, under the U.S. Clean Air Act, $\mathrm{CO}_{2}$ is a pollutant to be regulated. ${ }^{9}$ And anecdotally, some scientists have referred to excess atmospheric $\mathrm{CO}_{2}$ as waste to be disposed of like "sewage" (e.g., Lackner quoted in Magill 2016, Kolbert 2017 and Temple 2019a, b). Yet, virtually all studies of ICR proceed from the view that captured $\mathrm{CO}_{2}$ is a saleable commodity. Researchers therefore perform their analysis within a market framework in which commercial firms are the agents that will provide technological solutions; cost analyses are preeminent; and assumptions about theoretical market forces shape conclusions.

The view of captured $\mathrm{CO}_{2}$ as a saleable commodity is represented in the leading research reports by the IPCC and the U.S. National Academies of Sciences. The IPCC in its 2018 report suggested "pathways" in which "negative emissions technologies" could avert overshooting the global warming target ceiling of $1.5-2{ }^{\circ} \mathrm{C}$. The U.S. National Academies of Sciences (NAS) soon followed suit with its own "negative emissions technologies" (NETs) report (2019), vaunting NETs as an attractive commercial opportunity in the "international market":

This report's statements about the need for an emissions reduction of a particular amount should not be interpreted as normative statements (a value judgment on what should be), but rather as statements about the action required given a decision to meet the Paris agreement or to provide NETs to the international market created by such a decision by most nations, many corporations, and several U.S. states and local

\footnotetext{
${ }^{9} \mathrm{CO}_{2}$ has been classified as a pollutant under the Clean Air Act; see Supreme Court rulings in 2007 and 2014; subsequently, the EPA issued rules regulating $\mathrm{CO}_{2}$ as a pollutant (National Resources Defense Council 2007; Broder 2009; Barnes 2014).
} 
governments...The committee believes that its conclusions and recommendations are generally robust, simply because the economic rewards for success would be so large. (Emphasis in original.)

One consequence of such market-centrism, and the commodification of $\mathrm{CO}_{2}$ in carbon removal science, is that studies tend to ultimately gravitate toward a financial framing of processes' viability. And, in spite of their market framing, many of these papers nevertheless call for government action. The argument is that government should subsidize the development and deployment of ICR technologies so that, ostensibly, they can reach commercial viability. With the focus on finance and supposed commercial opportunity the impediments to scaling up ICR processes are presented in terms of financial needs rather than biophysical considerations. In effect, economics supersedes biophysics.

This pervasive market framing in carbon removal research has created a path dependency problem. That is, the commodification of $\mathrm{CO}_{2}$ in ICR research seems to constrain analyses to market-based solutions. This market frame is pervasive despite the reality that no viable market exists for the amount of $\mathrm{CO}_{2}$ that must be removed to have climatesignificant impact, as the financial analyses of most papers show, and as discussed earlier. Indeed, this lack of a market is the expressed reason papers call upon government to finance ICR. And, an even larger problem is that marketized thought can lead to studies in which an ICR process is deemed "mitigation" simply because it is claimed to reduce $\mathrm{CO}_{2}$ emissions compared to "conventional" emissions, even though overall emissions exceed removals. The pervasiveness of market framing seems to blind most researchers from seeing the implications of their findings and from considering or evaluating a non-market process-dedicated storage. Dedicated storage, not sale, of captured $\mathrm{CO}_{2}$ appears to be the only disposition of $\mathrm{CO}_{2}$ that can produce a net reduction of atmospheric $\mathrm{CO}_{2}$. And further, since point-source capture can at best, and only theoretically, sequester as much $\mathrm{CO}_{2}$ as is emitted, only renewable energy-powered direct air capture with dedicated storage could, in principle, actually reduce the stock of atmospheric $\mathrm{CO}_{2}$.

The alternative to viewing $\mathrm{CO}_{2}$ as a potential asset to be captured and sold for commercial gain is to understand excess atmospheric $\mathrm{CO}_{2}$ as a substance to be sequestered, in perpetuity. We will return to this view in the conclusion.

\section{Resource Usage}

In examining resource usage, our approach was to standardize for output in order to compare resource input requirements on a common basis. The output amount we standardized for is $1 \mathrm{GtCO}_{2}$ removal per year. We examined energy and land requirements at that level of capture.

\section{Resource Usage: Energy}

Direct Air Capture A few studies discuss the immense energy consumption of DAC when operated at scale. For example, Smith et al. (2016) reported that the energy requirements for a net removal of $\sim 3.3$ gigatons of carbon equivalents by amine DAC "would amount to a global energy requirement of $156 \mathrm{EJ}$ year $^{-1}$ if all energy costs are included. This is equivalent to $29 \%$ of total global energy use in 2013 (540 EJ year $\left.{ }^{-1}\right)$..." Translating these figures into $1 \mathrm{GtCO}_{2}$ removal yields 3580.9 terawatt hours, ${ }^{10}$ which is slightly more than the figure of 3417 terawatt hours reported by Climate Advisers (2018), and equates to nearly the total amount of electricity generated in the U.S. in 2017. Yet, even these amounts omit some downstream components of the DAC life cycle process, such as the energy requirements for transportation or sequestration of the captured $\mathrm{CO}_{2}$. Also omitted are the energy requirements for manufacturing sorbent at scale (Realmonte et al. 2019). Socolow et al. (2011), Smith et al. (2016), Climate Advisors (2018), House et al. (2011), Realmonte et al. (2019), and the U.S. National Academies of Sciences (2019) address energy consumption and are summarized in Online Appendix 3.

As described earlier, there is evidently a growing consensus that the direct air capture when fossil-fueled is thermodynamically counterproductive. The alternative routinely offered is to power the process using renewable energy. For example, the National Academy of Sciences negative emissions technologies report (2019) shows that net $\mathrm{CO}_{2}$ reductive emission-storage ratios can only with certainty be obtained when using non-carbon intensive power sources $\left(\gamma_{\mathrm{CO}_{2}}\right.$ ratios for solar energy are $0.0045-0.066$ and for nuclear energy 0.0022-0.032; ranges were only available for the solid-sorbent case). ${ }^{11}$

Yet, according to the energy requirements shown in Smith et al. (2016), renewables-powered DAC would require all of the wind and solar power generated in the U.S. in 2018 to capture just $1 / 10$ th $\mathrm{GtCO}_{2} \cdot{ }^{12}$ Realmonte et al (2019) projected that DAC would "use around a quarter of global energy demand to provide power and heat for DACCS technologies by the end of the century." Fridley and Heinberg (2018) note that the energy requirement for the fans alone in removing $1 \mathrm{GtCO}_{2}$ would be more than all the solar power

\footnotetext{
$\overline{10}$ Smith et al. (2016, p. 47); calculations performed by S. Davis, coauthor, Smith et al. Personal communication 8-19-18.

${ }^{11}$ Liquid solvent DAC plant technology requires high temperatures for the regeneration of carbon capture materials (up to $900{ }^{\circ} \mathrm{C}$ ) which is not possible with the application of renewable energy sources.

12 Calculations by Steven J. Davis, (Smith et al 2016 co-author); personal communication 8-19-19: U.S. Wind 2018- $\mathrm{CO}_{2}$ capture capability: 76.8 million tons. U.S. Solar $2018-\mathrm{CO}_{2}$ capture capability 26.8 million tons.
} 
generation in the U.S. in 2017_-based on Keith et al. (2018) who reported an energy requirement of $61 \mathrm{kWh} / \mathrm{tCO}_{2}$ for the fans alone. See Online Appendix 3 for more findings. Given the enormous energy requirements for direct air capture, the question for policymakers is whether to use public financing to divert renewable energy production to DAC or to support the development and deployment of renewables to power buildings, industry, and transport in order to directly curtail $\mathrm{CO}_{2}$ emissions.

Point-Source Capture CCS is more energy-efficient than DAC, since CCS captures the $\mathrm{CO}_{2}$ from the source of emission-generally power plants. However, a recent study argues that investments in renewables development would have better energetic returns than investments in CCS not even considering the $\mathrm{CO}_{2}$ being used for EOR. Sgouridis et al. (2019) have shown that investments in "renewable technologies generally provide a better energetic return than CCS." They found the energetic return on CCS projects to range from 6.6:1 and 21.3:1, whereas the energetic return on renewable electricity ranges from $9: 1$ to $30+: 1$. They conclude that "Therefore, renewables plus [battery] storage provide a more energetically effective approach to climate mitigation than constructing CCS fossil-fuel power stations."

\section{Resource Usage: Land}

There are three types of land requirements associated with industrial carbon dioxide removal: surface land for the capture process; surface land for pipeline transport of $\mathrm{CO}_{2}$; subsurface space, and surface land access, for geological storage.

Capture Process An important point for policymakers is that, while studies of carbon removal methods generally cite land requirements as a potential barrier to biological methods, few studies point to the tremendous land requirements for renewables-powered DAC. Most reports on DAC elide or ignore the land requirements of this method, which become enormous when operating at scale. CCS also has significant land requirements that are not addressed in many of the reports on this method. The other surface land requirement that usually lacks a prominent place the scientific literature is land for pipelines to transport the $\mathrm{CO}_{2}$ to injections sites-whether that be for EOR or for injection underground. And lastly, there is the subsurface space that is required for storage in perpetuity.

Most reports on direct air capture (DAC) elide or ignore the land requirements of this method, which become enormous when operating at scale, particularly if powered by renewable energy. To operate at scale (capture of $1 \mathrm{GtCO}_{2}$ ), a liquid solvent DAC system powered by natural gas would require a land area more than five (5) times the size of the city of Los Angeles. If solar is used to replace the fossil fuel power source, then the required land area expands dramatically: to remove $1 \mathrm{Gt}$ of $\mathrm{CO}_{2}$ would require a land area ten (10) times the size of the state of Delaware. These estimates are based on the National Academies of Sciences report on negative emissions technologies (2019), discussed further in Online Appendix 3. And this does not count the land required for transport, injection, and storage after the $\mathrm{CO}_{2}$ has been captured.

Transport: Pipelines Land Requirements A surface land requirement lacking a prominent place the scientific literature is the vast territory needed for pipelines to transport the captured $\mathrm{CO}_{2}$ to injection sites-whether for EOR or dedicated subsurface storage. One Gt of $\mathrm{CO}_{2}$ capture and transport would entail $\mathrm{CO}_{2}$ pipeline capacity larger than the existing petroleum pipeline system (Fridley ${ }^{13}$; Mac Mac Dowell et al 2017). Mac Mac Dowell et al. (2017) stress the enormous infrastructure buildout that would be required for $\mathrm{CO}_{2}$ capture and storage to operate at scale. "Given that CCS is expected to account for the mitigation of approximately 14-20\% of total anthropogenic $\mathrm{CO}_{2}$ emissions, in 2050 the CCS industry will need to be larger by a factor of 2-4 in volume terms than the current global oil industry." (See Online Appendix 3 for further detail.) DAC advocates often argue that DAC facilities can be located near injection sites, mooting the need for a vast pipeline network. But such assertions are generally made in promotional materials; they ignore the implications of operating DAC at scale and disregard the challenges of locating vast DAC facilities near suitable subsurface storage sites.

Subsurface Storage Estimates of the quantity of subsurface storage capacity in geological formations vary widely. The Congressional Research Service (CRS) (2020) cites U.S. Dept. of Energy estimate of storage capacity in the U.S.- - a wide range of from 2618 to $22,323 \mathrm{Gt}$ of $\mathrm{CO}_{2}$ (most being in saline formations). The IPCC (2005) estimated only 2000 Gt of worldwide storage capacity. Herzog (2011) noted, "it is not yet proven that enough storage capacity exists to support CCS at the gigaton scale..." Seto and McRae note that most storage capacity is in saline aquifers (which can lead to water contamination). A report by the European Academies, Science Advisory Council (EASAC) (2018) points out differences in global capacity estimates (citing Dooley 2013): a "theoretical" capacity of $35,300 \mathrm{GtCO}_{2}$, an "effective" capacity of $13,500 \mathrm{GtCO}_{2}$, and a "practical" capacity of $3900 \mathrm{GtCO}_{2}$. Zahaksy and Krevor (2020) project ample geological storage, estimating $2700 \mathrm{Gt}$ of "discovered stor-

\footnotetext{
${ }^{13}$ David Fridley, Fellow Post-Carbon Institute and Staff Scientist (retired), Lawrence Berkeley Laboratory; personal communications August and September 2019.
} 
age resource" with a capacity to "sustain peak injection rates of 40-60 Gt per year...", yet nowhere address whether such a massive capture of $\mathrm{CO}_{2}$ for dedicated storage is possible or plausible.

Other Resource Consumption Other resource requirements include water for the ICR process and materials for DAC sorbent production. Parts of the mechanical-chemical process use prodigious amounts of water; $\mathrm{CO}_{2}$ injection alone "would require an exorbitant amount of water" (Schlissel and Wamsted 2018). Chemical sorbent production for DAC at scale would require "a massive deployment" and "major refocusing of the manufacturing and chemical industries for sorbent production, and a large need for electricity and heat" according to Realmonte et al. (2019), who recommend that a "full life cycle assessment" of DAC be undertaken "to understand how its deployment drives energy demand for sorbent manufacture, as well as energy and material demand such as cement and steel...".

\section{Scale Issues}

Most scientific studies of industrial carbon removal do not acknowledge or address the massive level of effort that would be required to scale up in time to have meaningful climate impact, and many studies ignore or slight the known and potential biophysical repercussions of operating at scale. The scale of ICR at this time is negligible in relation to the excess concentration of $\mathrm{CO}_{2}$ in the atmosphere. Most studies that address the scaling-up challenge frame it as a financial problem. Only a few papers address biophysical and infrastructural issues of scaling up to a climate-significant level.

\section{Scale: Capture Capacity vs Scale Needed}

Over the last 250 years, since the beginning of the industrial revolution, the stock of atmospheric $\mathrm{CO}_{2}$ has substantially increased. Compared to pre-industrial levels which were about 280 ppm (World Economic Forum 2019) — a level that existed for several thousand years (Intergovernmental Panel on Climate Change 2018d), in 2020 the level reached 417 ppm (Scripps Institute of Oceanography 2020). Annual $\mathrm{CO}_{2}$ emissions have reached nearly 37Gt globally (Global Carbon Project 2019) and U.S. annual $\mathrm{CO}_{2}$ emissions were approximately 5.3 Gt in 2017 (Fleming 2019 and ourworldindata.org., undated) and 5.1 Gt in 2019 (U.S. Energy Information Association 2020). There is not a consensus on precisely what level of atmospheric $\mathrm{CO}_{2}$ is "safe," or what levels would avoid exceeding the $1.5^{\circ}$ Celsius or $2^{\circ}$ Celsius targets. Estimates have ranged from 350 ppm (McKibben citing Hansen in McKibben 2007) to 507 ppm (Met Office Weather Service 2018). According to Kemp (2019), IPCC scientists "have estimated the limits imply an atmospheric
$\mathrm{CO} 2$ concentration of no more than 450 parts per million (for 2 degrees) or 430 ppm (for 1.5 degrees)."

The amount of $\mathrm{CO}_{2}$ being captured and stored through CCS/CCUS and DAC currently is negligible in relation to the excess concentration of $\mathrm{CO}_{2}$ in the atmosphere, and in comparison to projected need (Mac Dowell et al. 2017; Minx et al 2018; Fuss et al 2018; Nemet et al 2018; Honegger and Reiner 2017; Jacobson 2019; Herzog 2011). Reported ICR capture capacity (primarily point-source capture) is currently 2.4 million tonnes in N. America and 1.7 million tonnes in Europe for a total of 4.1 million tonnes ${ }^{14}$ which amounts to $0.0041 \mathrm{Gt}$. This amount is negligible in comparison to the projected need, e.g., a study by Mac Dowell et al. (2017) calculates that a global sequestration rate of $2.5 \mathrm{GtCO}_{2}$ per year is needed by 2030, increasing to 8 to $10 \mathrm{Gt}$ per year by 2050 . The U.S. National Academies of Sciences (2019) estimates that NETs will need to remove $\sim 10 \mathrm{Gt} /$ year $\mathrm{CO}_{2}$ globally by mid-century. The current scale of NET capture is insignificant in comparison. The largest DAC facility globally captures only $4000 \mathrm{tCO}_{2}$ /year (Peters 2019; Soltoff 2019), which is only $0.000004 \mathrm{Gt}$. The next largest DAC facilities capture only one to "a few" tons a day which annually amounts to a few hundred tons (Rathi 2018, 2019). One unbuilt DAC facility aspires to capture $36,500 \mathrm{tCO}_{2}$ /year (Malo 2019), which is still negligible: only $0.0000365 \mathrm{Gt}$, and another aspires to one million tons per year (Geman 2020), which is still only one one-thousandth of a $\mathrm{Gt}$ (and the captured $\mathrm{CO}_{2}$ will be used for enhanced oil recovery). The U.S. National Academies of Sciences (2019), in writing about all forms of NETs, cautions that "Any argument to delay mitigation efforts because NETs will provide a backstop drastically misrepresents their current capacities and the likely pace of research progress."

\section{Scale: Biophysical Impacts}

Storage of $\mathrm{CO}_{2}$ captured through mechanical-chemical methods requires injection of $\mathrm{CO}_{2}$ into a suitable subsurface geological formation, which raises a variety of issues: quality and quantity of suitable storage sites (discussed above); potential lack of permanence of storage (Bruhn et al. 2016; Congressional Research Service 2018); leakage (European Academies, Science Advisory Council 2018); fugitive emissions (Stewart and Haszeldine 2015); potential groundwater

\footnotetext{
14 The World Coal Association and the Global CCS Institute both broadcast "96 million tonnes" as an "estimated capture capacity" but most of that is from plants not yet built or not yet in operation. https://www.worldcoal.org/reducing-co2-emissions/carbon-captureuse-storage; https://www.globalccsinstitute.com/news-media/press -room/media-releases/new-wave-of-ccs-activity-ten-large-scale-proje cts-announced/ China's operational CCS project started in 2019, so there are not historical data on capture capacity. https://energynews .us/2020/03/30/midwest/can-this-north-dakota-co-op-prove-the-poten tial-of-carbon-capture-and-storage/
} 
contamination and earthquakes (Clean Water Action 2017); air pollution and health damage (Jacobson 2019); and liability for environmental and health problems (Herzog 2011). (See Online Appendix 3 for detail.) Most captured $\mathrm{CO}_{2}$ is currently used for EOR (as discussed earlier); the $\mathrm{CO}_{2}$ is injected into an oil reservoir where it is meant to remain in perpetuity. Other locations for storage are saline formations and unmineable coal seams (Herzog 2011). But there is almost no experience with large-scale, commercial geologic storage (Congressional Research Service 2020a, b), and only two low-volume, dedicated storage commercial sites in Norway (which operate based on government incentives). The hallmark of geologic storage is uncertainty (Boot-Hanford et al. 2014).

Legislation would be required to assure standards are in place to avert or reduce the biophysical impacts of mechanical-chemical $\mathrm{CO}_{2}$ capture and storage.

Also an extensive monitoring, measuring, verification, and data tracking system would be required to verify storage and detect and monitor leakage, air and water quality, seismic activity, and other ancillary effects from subsurface storage. (Dooley 2010; Herzog 2011; Boot-Hanford et al. 2014; Stewart and Haszeldine 2014; International Energy Agency 2015; Smith et al. 2016; Nemet et al. 2018; Schlissel and Wamsted 2018; Realmonte et al. 2019; Nunez-Lopez and Moskal 2019; Muffett and Feit 2019). The sensing and tracking technology and network could constitute a new "Internet of Carbon" (Buck 2018), which, itself, raises questions of additional energy consumption and resulting additional $\mathrm{CO}_{2}$ emissions, land requirements, and intellectual property (IP) rights to such technology.

\section{Scale: Mobilization Required}

Of the few authors who have addressed the scale issue from a biophysical perspective, several have emphasized that the scale of effort that would be needed is equivalent to "wartime mobilization." Here is Mac Dowell et al. (2017):

Given that CCS is expected to account for the mitigation of approximately $14-20 \%$ of total anthropogenic $\mathrm{CO}_{2}$ emissions, in 2050 the CCS industry will need to be larger by a factor of 2-4 in volume terms than the current global oil industry. In other words, we have 35 years to deploy an industry that is substantially larger than one which has been developed over approximately the last century...This is an exceptionally challenging task, similar in scale to wartime mobilization. (Emphasis added.)

The Climate Investigations Center (2019) and Barnard (2019) describe the "massive" amounts of costly infrastructure" that would be required in order to operate at scale. Romm (2008) wrote more than a decade ago that
" $450[\mathrm{ppm}]$ needs a World War II-scale effort starting in the next decade."

\section{Conclusions and Recommendations}

\section{Conclusions}

Our overall policy finding is that the scientific literature does not support the use of public funds to subsidize the commercial development and deployment of ICR, especially those methods that have been shown to emit more $\mathrm{CO}_{2}$ than they sequester, thereby adding to the existing stock of atmospheric $\mathrm{CO}_{2}$. In specific, these methods are (1) any process in which captured $\mathrm{CO}_{2}$ is used for enhanced oil recovery (EOR); and (2) direct air capture (DAC) when fossil fuelpowered. Furthermore, the current ICR path disregards known risks of chemically intensive, industrial carbon removal, and the adverse side effects and subsurface storage uncertainty at scale.

It is troubling that the biophysical issues of operating ICR at scale are insufficiently addressed or analyzed in the ICR literature. Legislators, too, have neglected to address the biophysical requirements for and consequences of operating ICR at climate-significant scale. As DAC increasingly takes prominence among carbon removal advocates, it is problematic that the issues of DAC energy consumption are short-shrifted. Scientific and technical papers increasingly acknowledge that fossil fuel-powered DAC is thermodynamically counterproductive, yet these same papers fail to tackle the consequential question of whether renewable energy should be funneled to DAC rather than used to directly supply energy for buildings and transport. Virtually ignored in legislation, and unacknowledged in many reports advocating CCS/CCUS and DAC, are the massive land requirements for DAC operation as well as land requirements (acquisition and occupancy) for pipelines for $\mathrm{CO}_{2}$ transport. Also slighted or ignored in both policymaking and most of the literature are other biophysical costs like the prodigious amount of chemicals needed for direct air capture (DAC) to operate at scale. In addition, one must consider the adverse biophysical impacts of massive $\mathrm{CO}_{2}$ transport and storage operations and infrastructure, including potential fugitive emissions, groundwater contamination, air pollution, and earthquakes. Lastly, both legislation and most of the literature ignore the "wartime level of effort" that would be required to scale-up to a climate-significant level of operation.

Our review of legislation, policy actions, and policyoriented reports shows that government decisions on carbon removal are largely driven by the question of commercial viability. Public policy decisions are being finance-driven, not science-driven. The market frame is pervasive even though, as many studies show-and almost 
all acknowledge - no viable market exists for the amount of $\mathrm{CO}_{2}$ that must be removed and sequestered in order to have climate-significant impact. Although clothed in the mantle of the market, studies call for government subsidy. Also illogically, papers advocating $\mathrm{CO}_{2}$ "utilization" frequently employ a partial LCA that ignores emissions from the commercial uses to which captured $\mathrm{CO}_{2}$ is put. The history of government subsidies for renewable energy development is frequently advanced as the rationale for why government should subsidize the private development of industrial carbon removal. Early-stage subsidies built the platform for later-stage market success of solar and wind, and, it is argued, the same should be done for DAC. This argument is faulty. Unlike energy generated from solar or wind, for which there is a market, there is not, and cannot be, a "market" for burying $\mathrm{CO}_{2}$. (The dubiousness of an effective market for "carbon credits" has been widely documented; regardless, that is not the same thing as a market for captured carbon.) Paying the cost of $\mathrm{CO}_{2}$ subsurface storage is a non-market transaction. There is no "customer;" there is only the single payor-government-which pays for the service from the collective resources of the polity (Studenski 1939; Ranson and Stewart 1989; Stretton and Orchard 1994; Sekera 2016).

The current path also foregoes the benefits of biological carbon sequestration, which in the U.S. in particular has been dismissed by many policymakers and legislators. Public subsidy in the near-term of commercial ICR methods can create long-term "lock-in" (Erickson et al. 2015; SEI, IISD, ODI, Climate Analytics, CICERO \& UNEP 2019) of the fossil fuel industry as the holder of the expertise and owner of the infrastructure (Buck 2018) and the intellectual property (IP) that would be necessary should governments decide that scaling up to a wartime level of mobilization is necessary.

Dedicated storage, not sale, of captured $\mathrm{CO}_{2}$ appears to be the only assured way that mechanical-chemical CCS could meet the societal need of absolute reduction of atmospheric $\mathrm{CO}_{2}$. A carbon removal process in which captured $\mathrm{CO}_{2}$ is merely injected into underground strata for perpetual storage (rather than being sold for commercial gain) may be net $\mathrm{CO}_{2}$ negative overall. However, simply injecting captured carbon into the earth is not commercially viable. (See Online Appendix 4)

We conclude that governments should approach atmospheric $\mathrm{CO}_{2}$ reduction as a public service like water treatment or waste disposal. Some have alluded to this public-interest approach, in which atmospheric carbon dioxide reduction is seen as a "public good" (Mulligan et al. 2018b) or a "collective social good...[wherein] carbon capture and sequestration would be the world's most massive pollution clean-up operation, conducted as a public service" (Buck 2018). Buck hypothesized "public funding for research and development, public ownership of carbon removal technologies and data [and] public sector jobs in carbon removal". Importantly, one of the early developers of direct air capture, Klaus Lackner, has said that $\mathrm{CO}_{2}$ removal should be treated like waste removal: $\mathrm{CO}_{2}$ needs to be collected and disposed of like garbage or sewage (Lackner quoted in Magill 2016; Kolbert 2017; Temple 2019a, b).

If massive, government-funded carbon reduction is deemed essential, then a more coherent assessment of alternative methods is needed than has yet taken place in the public policy arena.

\section{Recommendations}

We make three types of recommendations:

- Action on legislation already in effect and currently being considered;

- Principles for legislation that would treat atmospheric carbon dioxide reduction as a public service; and

- Development of a policy instrument for evaluating the options for atmospheric $\mathrm{CO}_{2}$ reduction on a standardized, biophysical basis.

\section{Legislation}

\section{Existing Carbon Removal Legislation in Effect or Under Con-} sideration Lawmakers should

(1) remove existing subsidies for $\mathrm{CO}_{2}$-EOR;

(2) specify that the captured $\mathrm{CO}_{2}$ cannot be used for fossil fuel production; and

(3) specify that the amount of $\mathrm{CO}_{2}$ removed by the process must exceed the amount of $\mathrm{CO}_{2}$ emitted by the process over the entire life cycle of the process (including sourcing of $\mathrm{CO}_{2}$ and consumption of fuel or other products produced).

Atmospheric Carbon Reduction as a Public Service: An Alternative Legislative Agenda Lawmakers should approach atmospheric carbon dioxide reduction as public service to meet a societal need, which is to achieve an absolute reduction in atmospheric $\mathrm{CO}_{2}$. This means that dedicated sequestration-not sale-of $\mathrm{CO}_{2}$ is the public policy path. From the perspective of public lawmaking, captured $\mathrm{CO}_{2}$ must be regarded as a pollutant rather than a commercial commodity. (In the U.S., $\mathrm{CO}_{2}$ has been classified as a pollutant. ${ }^{15}$ )

\footnotetext{
${ }^{15} \mathrm{CO}_{2}$ has been classified as a pollutant under the Clean Air Act; see Supreme Court rulings in 2007 and 2014; subsequently, the EPA issued rules regulating $\mathrm{CO}_{2}$ as a pollutant (National Resources Defense Council 2007; Broder 2009; Barnes 2014).
} 
Point-Source Capture vs Direct Air Capture A public purpose perspective requires differing policy approaches for point-source capture and direct air capture.

\section{Point-Source Capture}

Point-source capture should receive no public subsidy. This method does not remove $\mathrm{CO}_{2}$ from the atmosphere and so does not reduce the stock of atmospheric $\mathrm{CO}_{2}$. Its aim is to reduce the amount of new $\mathrm{CO}_{2}$ being emitted. As such, it reduces a "negative externality" produced by fossil fuel combustion. The cost of such reduction should be borne by the producer, not by society. This position is in line with the "polluter pays principle"-a long-standing tenet in environmental law. Therefore, legislation should be enacted to require that all fossil-fueled power facilities use carbon capture technology to avert or reduce $\mathrm{CO}_{2}$ emissions at the producers' expense. (A conventional economics analysis would argue that the cost would ultimately be borne by utility ratepayers, but that possibility can be avoided through adroitly designed legislation.)

\section{Direct Air Capture}

Direct air capture can likely reduce the stock of atmospheric $\mathrm{CO}_{2}$ if powered by non-carbon fuel sources and if the captured $\mathrm{CO}_{2}$ is simply sequestered rather than being reused. (Whether the immense amounts of renewable energy that would be required should be used for DAC or, instead, used directly to reduce emissions by powering homes, businesses, transportation, etc., is a different public policy question.)

If government financing, or subsidy in any form, is used to develop, deploy, or operate DAC (or any atmospheric carbon dioxide capture and sequestration technology), then the accompanying or resultant intellectual property (IP) rights and patents should be held by the public (the government that provided the financing). The talent/expertise should reside in the public sector and mission control should rest in the hands of professional public servants whose mission is to meet societal needs. In sum, if society is collectively financing the development and use of technology for DAC, then that technology should be collectively owned, and the technical expertise should be resident in the public domain.

\section{Storage}

In a public service context, $\mathrm{CO}_{2}$ captured through mechanical-chemical methods would be injected underground and stored in perpetuity. A "wartime level of mobilization" would be required in order to have a climate-significant impact on the level of atmospheric $\mathrm{CO}_{2}$. Besides the construction of enormous DAC plants and facilities, this would entail massive buildout of infrastructure and pipelines for transport to subsurface storage sites. It also would require long-term monitoring for fugitive emissions, blowouts, seismic events, groundwater contamination, and other ancillary impacts. As a public service, the costs would be collectively borne.

However, based on the evidence from our study, the question for policymakers is whether industrial-mechanical carbon removal is a realistic option and, therefore, whether it should even be part of the policy mix. Thus, before embarking on any legislation for such massive, industrial operations, policymakers and lawmakers need first to evaluate the comparative effectiveness and efficiency of biological methods of carbon drawdown and sequestration.

\section{Policy Analysis Tool}

As things now stand, policymakers-and voters-have been deprived of the necessary context within which to make informed decisions-or as Chabbi et al. (2017) put it: to "appl[y] science to societal needs." For informed decision-making about carbon sequestration, we must evaluate effectiveness and efficiency of both biological methods and mechanical-chemical methods on a standardized, biophysical basis. A tool for such comparison does not now exist. ${ }^{16}$ We propose the development of a policy analysis instrument to enable the biophysical comparison of all carbon removal and sequestration methods-biological and mechanical-chemical. The idea of a policy analysis tool is an adaptation of recommendations in Costanza et al. (1997, pp. 187-188), who emphasize the crucial importance of "policies and instruments" for assessing the thermodynamic effects of alternative technologies. The idea also builds off the "energy return on energy invested" (EROI) tool (Hall 2017). However, rather than measuring energy input and output, as in EROI, this tool would enable a standardized assessment of resource consumption (inputs to a process) and the biophysical impacts of that consumption (outcomes from a process).

The components of a policy analysis tool would be:

o Impact on carbon balance A standardized effectiveness analysis that evaluates impact on the stock of atmospheric $\mathrm{CO}_{2}$ : Does the process sequester more $\mathrm{CO}_{2}$ than is emitted by the full process? Does it reduce the stock of atmospheric $\mathrm{CO}_{2}$ ?

o Resource usage at scale A standardized analysis that answers the questions-At $1 \mathrm{Gt}$ atmospheric $\mathrm{CO}_{2}$ reduc-

\footnotetext{
${ }^{16}$ As explained in this article, the numerous studies that do exist contain inconsistent findings and exist in formats-in both language and notation-that are not accessible to the layperson. Existing studies do not provide a standardized basis for a comparative evaluation of various methods from the perspective of biophysical collective need.
} 
tion: How much energy and water are consumed by a process? How much land is required?

o Biophysical impacts at scale At $1 \mathrm{Gt}$ atmospheric $\mathrm{CO}_{2}$ reduction, what are the ancillary impacts of the process in terms of other biophysical gains or losses?

The information derived from a such a policy analysis instrument could inform both policymakers and the public. The data derived from such a tool could also serve as a basis for setting standards (Galbraith 2018; Goodwin 2018) for public policy formulation.

In sum, in order to evaluate alternative methods of atmospheric carbon dioxide reduction from a collective biophysical need perspective, we must move from a market-centric view to a "biocentric view" (Daly 2019), and from the market framework that constrains most extant research and reporting, to a "biophysical framework" (Galbraith 2014, p. 238). As it stands now, governments lack an "objective standard of value" (Mazzucato 2018, p. 62) by which to formulate their policy decisions about atmospheric carbon reduction. As Herman Daly (2005) tells us in "The Illth of Nations and the Fecklessness of Policy," we need a "real criterion of value by which to choose from among the alternatives. Unless we can distinguish better from worse states of the world then it makes no sense to try to achieve one state of the world rather than another...Through our choices, value and purpose lure the physical world in one direction rather than the other. Purpose is independently causative in the world."

Acknowledgements We are deeply appreciative to Charles A. S. Hall for reviews of drafts of this article and invaluable feedback. Initial research for this project was supported by a grant from the Rockefeller Family Fund.

\section{Compliance with Ethical Standards}

\section{Conflict of Interest There are no conflicts of interest.}

Open Access This article is licensed under a Creative Commons Attribution 4.0 International License, which permits use, sharing, adaptation, distribution and reproduction in any medium or format, as long as you give appropriate credit to the original author(s) and the source, provide a link to the Creative Commons licence, and indicate if changes were made. The images or other third party material in this article are included in the article's Creative Commons licence, unless indicated otherwise in a credit line to the material. If material is not included in the article's Creative Commons licence and your intended use is not permitted by statutory regulation or exceeds the permitted use, you will need to obtain permission directly from the copyright holder. To view a copy of this licence, visit http://creativecommons.org/licenses/by/4.0/.

\section{References}

Adlen E, Hepburn C (2019) Ten ways to use $\mathrm{CO}_{2}$ and how they compare. CarbonBrief

Allwood JM et al (2019) Absolute zero. Delivering the UK's climate change commitment with incremental changes to today's technologies. University of Cambridge

Anderson K, Peters G (2016) The trouble with negative emissions. Science 354(6309):182-183

Armstrong K, Peter S (2015) Assessing the potential of utilization and storage strategies for post-combustion $\mathrm{CO}_{2}$ emissions reduction. Front Energy Res

Azzolina NA, Peck WD, Hamling JD, Gorecki CD (2016) How green is my oil? A detailed look at greenhouse gas accounting for $\mathrm{CO} 2$-enhanced oil recovery (CO2-EOR) sites. Int J Greenhouse Gas Control 51:369-379

Baena-Moreno F et al (2019) Carbon capture and utilization technologies: a literature review and recent advances. Energy Sources Part A 41(12):1403-1433

Bai X, Huang Y, Ren W, Coyne M, Jacinthe P-A, Tao Bo, Hui D, Yang J, Matocha C (2019) Responses of soil carbon sequestration to climate-smart agricultural practices: a meta-analysis. Glob Change Biol 019:1-16

Baker M (2020) To fight climate change, one city may ban natural gas to heat homes. New York Times

Barnard M (2019) Air carbon capture's scale problem: 1.1 Astrodomes for a ton of $\mathrm{CO}_{2}$. Clean Technica

Barnes R (2014) Supreme court: EPA can regulate greenhouse gas emissions, with some limits. Washington Post

Bastin J-F et al (2019) The global tree restoration potential. Science 365:76-79

Bennett SJ et al (2014) Towards a framework for discussing and assessing $\mathrm{CO}_{2}$ utilisaton in a climate context. Energy Procedia 63:7976-7992

Bernal B, Murray LT, Pearson TRH (2018) Global carbon dioxide removal rates from forest landscape restoration activities. Carbon Bal Manag 13:22

Blum J (2019) Oxy moves forward on Permian 'direct air capture' plant. Houston Chronicle

Boot-Hanford ME et al (2014) Carbon capture and storage update. Energy Environ Sci 7:130

Broder JM (2009) E.P.A. clears way for greenhouse gas rules. New York Times

Bruhn T, Naims H, Olfe-Kräutlein B (2016) Separating the debate on $\mathrm{CO} 2$ utilization from carbon capture and storage. Environ Sci Policy 60:38-43

Buck HJ (2018) The need for carbon removal. Jacobin Magazine

Chabbi A et al (2017) Aligning agriculture and climate policy. Nat Clim Change 7:307-309

Chalmin A (2019) Direct air capture: recent developments and future plans. Geoengineering Monitor

Chichilnisky G (2019) Direct air capture: the key to reversing climate change. Biofuels Digest

Clean Water Action (2017) Carbon Dioxide EOR - A Threat to Water and the Environment - Nov. 2017.pdf

Clean Water Fund (2017) Carbon dioxide EOR - a threat to water and the environment. https://www.cleanwaterfund.org/publications/ carbon-dioxide-enhanced-oil-recovery-co2-eor

Clemens K (2019) $\mathrm{CO}_{2}$ converted to solid carbon. Design News

Climate Advisers (2018) Creating negative emissions; The role of natural and technological carbon dioxide removal strategies

Climate Investigations Center (2019) Carbon capture: expensive pipe dream or 'Holy Grail'?'. https://climateinvestigations.org/carbo n-capture-sequestration-ccs/ 
Colm G (1936) Theory of public expenditures. AnnAm Acad Polit Soc Sci 183:1-11

Committee on Climate Change (2019) Net Zero; The UK's contribution to stopping global warming

Congressional Research Service (2018) Carbon capture and sequestration in the United States

Congressional Research Service (2020a) Injection and geologic sequestration of carbon dioxide: federal role and issues for Congress, Angela C. Jones. https://crsreports.congress.gov

Congressional Research Service (2020b) The tax credit for carbon sequestration (Section 45Q)

Cooney G, Littlefield J, Marriott J, Skone T (2015) Evaluating the climate benefits of $\mathrm{CO}_{2}$-enhanced oil recovery using life cycle analysis. Environ Sci Technol 49:491-7500

Costanza R, Cumberland J, Daly H, Goodland R, Norgaard R (1997) An introduction to ecological economics. International Society for Ecological Economics, CRC Press

Cresswell J (2019) Solving the carbon conundrum. Energy Voice

Cuellar-Franca RM, Azapagic A (2015) Carbon capture, storage and utilization technologies: a critical analysis and comparison of their life cycle environmental impacts. J CO2 Util 9:82

Cusick M (2020) Pennsylvania lawmaker hopes carbon capture can bridge partisan divide over climate change. energynews.us

Daly HE (2005) The Illth of nations and the fecklessness of policy: an ecological economist's perspective. Post-Autistic Economics Review No. 30

Daly H (2019) Growthism: its ecological, economic and ethical limits. Real-World Economics Review No. 87

Davis SJ et al (2018) Net-zero emissions energy systems. Science 360:eaas9793

Desmarais-Tremblay M (2017) Musgrave, Samuelson, and the crystallization of the standard rational for public goods. Hist Polit Econ 49:1

Diamandis PH (2019) The promise of direct air capture: making stuff out of thin air. Singularityhub

Dismukes DE, Layne M, Snyder BF (2018) Understanding the challenges of industrial carbon capture and storage: an example in a U.S. petrochemical corridor. Int J Sustain Energy 38:13

Dooley J (2013) Estimating the supply and demand for deep geologic $\mathrm{CO}_{2}$ storage capacity over the course of the 21 st century: a metaanalysis of the literature. Energy Procedia 37:5141-5150

Dooley JJ, Dahowski RT, Davidson CL (2010) $\mathrm{CO}_{2}$-driven enhanced oil recovery as a stepping stone to what?. Technical Report PNNL-19557 Pacific Northwest National Laboratory by Battelle for the United States Department of Energy

Dooley $\mathrm{K}$ et al (2018a) Missing pathways to $1.5^{\circ} \mathrm{C}$ : the role of the land sector in ambitious climate action. Climate Land Ambition and Rights Alliance

Dooley K, Christoff P, Nicholas KA (2018) Co-producing climate policy and negative emissions: trade-offs for sustainable landuse. Global Sustain 1(e3):1-10

Erickson P, Kartha S, Lazarus M, Tempest K (2015) Assessing carbon lock-in. Environ Res Lett 10(8):084023. https://doi. org/10.1088/1748-9326/10/8/084023

European Academies, Science Advisory Council (EASAC) (2018) Negative emission technologies: what role in meeting Paris Agreement targets? EASAC

Evans S (2017) The Swiss company hoping to capture 1\% of global $\mathrm{CO}_{2}$ emissions by 2025. www.carbonbrief.org

ExxonMobil (2019a) https://www.ispot.tv/ad/IW6P/exxon-mobil-carbo n-capture

ExxonMobil (2019b) ExxonMobil and Global Thermostat to advance breakthrough atmospheric carbon capture technology.

Faltinson J, Gunter B (2011) Net $\mathrm{CO}_{2}$ stored in North American EOR Projects. J Can Pet Technol 50:55
Fargione JE, Bassett S, Boucher T et al (2018) Natural climate solutions for the United States.Sci Adv 4(11): 1869

Fleming S (2019) Chart of the day: these countries create most of the World's CO2 emissions. World Economic Forum. https://www. weforum.org/agenda/2019/06/chart-of-the-day-these-countriescreate-most-of-the-world-s-co2-emissions/

Foehringer Merchant E (2018) With 43 carbon-capture projects lined up worldwide, supporters cheer industry momentum. GreentechMedia

Frazin R (2020) Government probe finds companies claiming carbon capture tax credit didn't follow EPA requirements. www.thehi 11.com

Fridley D, Heinberg R (2018) Can climate change be stopped by turning air into gasoline? Renewable Energy World

Fuss S, Lamb WF, Callaghan MW et al (2018) Negative emissionsPart 2: costs, potentials and side effects. Environ Res Lett 13:063002

Galbraith JK (2014) The end of normal. Simon \& Schuster, New York

Galbraith JK (2018) The need for a new public administration. RealWorld Econ Rev 84:170-177

Galbraith JK (1958) The affluent society. Houghton Mifflin, Boston

Geman B (2020) Occidental Petroleum teams with private equity firm to deploy carbon capture tech in U.S. www.axios.com

Global CCS Institute (2018) The Global Status of CCS 2018. Global CCS Institute

Global CCS Institute (2019b) New wave of CCS activity: ten largescale projects announced. Global CCS Institute

Global CCS Institute (undated) https://web.archive.org/web/20180 704230257/http://www.globalccsinstitute.com/projects/co2-utili sation-projects. Accessed 30 May 2020

Global Carbon Project; "Global Carbon Budget" (2019) https://www. globalcarbonproject.org/carbonbudget/19/highlights.htm.

Godec ML, Kuuskraa VA, Dipietro P (2013) Opportunities for utilizing anthropogenic $\mathrm{CO}_{2}$ for enhanced oil recovery and $\mathrm{CO}_{2}$ storage. Energy Fuels 8:4183

Goodwin N (2018) There is more than one economy. Real-World Econ Rev 84:16-35

Goodwin NR, Harris J, Nelson JA, Roach B, Torras M (2014) Principles of economics in context. M E Sharpe, Armonk

Groesbeck JG, Pearce JM (2018) Coal with carbon capture and sequestration is not as land use efficient as solar photovoltaic technology for climate neutral electricity production. Nat Sci Rep 8:13476

Griscom BW, Adams J, Ellis PW, Houghton RA et al (2017) Natural climate solutions. PNAS 114(44)

Gunther M (2011) The business of cooling the planet. Fortune

Gunther M (2012a) Rethinking carbon dioxide: from a pollutant to an asset. Yale e 360

Gunther M (2012b) Direct air capture of $\mathrm{CO}_{2}$ is becoming a business, for better or worse. energycentral.com

Hackett D (2018) Carbon capture and utilization for enhanced oil recovery. Stillwater Associates

Hall CAS (2017) Will EROI be the primary determinant of our economic future? The view of the natural scientist versus the economist. Joule 1:635-638

Hayde E, Semmler W (2018) The dynamics of negative carbon emissions: the case of forestry. researchgate.net

$\mathrm{He} \mathrm{Y}$ et al (2016) Radiocarbon constraints imply reduced carbon uptake by soils during the $21^{\text {st }}$ century. Science 353:1419-1424

Hepburn C et al (2019) The technological and economic prospects for $\mathrm{CO}_{2}$ utilization and removal. Nature 575:87

Hertwich EG et al (2008) Life-cycle assessment of carbon dioxide capture for enhanced oil recovery. Chin J Chem Eng 16(3):343-353

Herzog HJ (2011) Scaling up carbon dioxide capture and storage: from megatons to gigatons. Energy Economics 33:597-604 
Hodgson GM (2013) From pleasure machines to moral communities: an evolutionary economics without homo economicus. University of Chicago, Chicago

Honegger M, Reiner D (2017) The political economy of negative emissions technologies: consequences for international policy design. Clim Policy 18(3):306

Houghton RA, Nassikas AA (2018) Negative emissions from stopping deforestation and forest degradation, globally. Glob Change Biol 24(1):350-359. https://doi.org/10.1111/gcb.13876

House KZ, House CH, Schrag DP, Aziz MJ (2007) Electrochemical acceleration of chemical weathering as an energetically feasible approach to mitigating anthropogenic climate change. Environ Sci Technol 41:8464-8470

House KZ, Baclig AC, Ranjan M, Nierop EA, Wilcox J, Herzog HJ (2011) Economic and energetic analysis of capturing $\mathrm{CO}_{2}$ from ambient air. PNAS 108:20428

Hovorka S, Tinker SW (2010) EOR as sequestration: geoscience perspective: presented at the symposium on the role of enhanced oil recovery in accelerating the deployment of carbon capture and storage. GCCC Digital Publication Series \#10-12, Cambridge, MA

Hulac BJ (2020) Treasury IG: a decade of carbon-capture tax credits were faulty. www.rollcall.com

Hussain D, Dzombak DA, Jaramillo P, Lowry GV (2013) Evaluation of technology and policy issues associated with the storage of carbon dioxide via enhanced oil recovery in determining the potential for carbon negative oil. Int J Greenhouse Gas Control 16:129-144

Intergovernmental Panel on Climate Change (2018a) Global warming of $1.5^{\circ} \mathrm{C}$; summary for policymakers.https://www.ipcc.ch/sr15/ chapter/spm/

Intergovernmental Panel on Climate Change (2018d) The carbon cycle and atmospheric carbon dioxide. https://www.ipcc.ch/site/assets/ uploads/2018/02/TAR-03.pdf

Intergovernmental Panel on Climate Change (2014b) Climate Change 2014: mitigation of climate change. Contribution of working group III to the fifth assessment report of the intergovernmental panel on climate change, Chapter 7.Cambridge University Press, Cambridge, UK

Intergovernmental Panel on Climate Change (2005) Carbon dioxide capture and storage. Cambridge University Press, New York

International Energy Agency (2019) Tracking report. https://www.iea. org/reports/tracking-power-2019/ccus-in-power

International Energy Agency (IEA) (2015) Storing $\mathrm{CO}_{2}$ through Enhanced Oil Recovery; Combining EOR with CO@ storage $(\mathrm{EOR}+)$ for profit. International Energy Agency

Jacobson MZ (2019) The health and climate impacts of carbon capture and direct air capture. Energy Environ Sci. https://doi. org/10.1039/C9EE02709B

Jaramillo P, Griffin WM, McCoy ST (2009) Life cycle inventory of $\mathrm{CO}_{2}$ in an enhanced oil recovery system. Environ Sci Technol 43(21):8027

Johnson D (undated) Why not soil carbon? Atmospheric $\mathrm{CO}_{2}$ reduction in soils of agroecosystems-a logical, practical and economical solution. https://www.csuchico.edu/regenerativeagr iculture/_assets/documents/research-david-johnson-atmospheri c-co2-reduction-final.pdf

Kane D (2015) Carbon sequestration potential on agricultural lands: a review of current science and available practices. National Sustainable Agriculture Coalition and Breakthrough Strategies and Solutions, LLC

Keith D et al (2018) A process for capturing $\mathrm{CO}_{2}$ from the atmosphere. Joule 2:1573

Kemp J (2019) Climate change targets are slipping out of reach. Reuters

Kolbert E (2017) Can carbon-dioxide removal save the world? New Yorker
Kolster C et al (2017) $\mathrm{CO}_{2}$ enhanced oil recovery: a catalyst for gigatonne-scale carbon capture and storage deployment? Energy Environ Sci 10(12):2594-2608

Lacy R, Molina M, Vaca M, Serralde C, Hernandez G, Rios G et al (2015) Life-cycle GHG assessment of carbon capture, use and geological storage (CCUS) for linked primary energy and electricity production. Int J Greenhouse Gas Control 42:165-174

LaFollette N (2018) Nemet, colleagues review negative emission technologies for reducing CO2. La Follette School of Public Affairs, University of Wisconsin-Madison, Robert M

Lal $\mathrm{R}$ et al (2018) The carbon sequestration potential of terrestrial ecosystems. J Soil Water Conserv 73(6):145A

Liu Y, Ge J, Liu C, He R (2020) Evaluating the energy consumption and air emissions of $\mathrm{CO}_{2}$-enhanced oil recovery in China: a partial life cycle assessment of extra low permeability reservoirs. Int J Greenh Gas Control 92:102850

Mac Dowell N et al (2017) The role of CO2 capture and utilization in mitigating climate change. Nature Climate Change 7:243-249

Magill B (2016) $\mathrm{CO}_{2}$, climate change see as waste disposal challenge. Climate Central

Malo S (2019) Do 'mechanical trees' offer the cure for climate change? Reuters

Marshall C (2019) Oil industry makes landmark investment in $\mathrm{CO}_{2}$ air capture. E\&E News

Martin D et al (2017) Carbon dioxide removal options: a literature review identifying carbon removal potentials and costs

Mazzucato M (2018) The value of everything, Allen Lane

McCormick M (2012) A greenhouse gas accounting framework for carbon capture and storage projects. Center for Climate and Energy Solutions

McKibben B (2007) remember this: 350 parts per million. Washington Post

Mendelevitch R (2013) The role of $\mathrm{CO}_{2}$-EOR for the development of a CCTS infrastructure in the North Sea Region. DIW Berlin.

Met Office Weather Service (2016) How much $\mathrm{CO}_{2}$ at $1.5^{\circ} \mathrm{C}$ and $2{ }^{\circ} \mathrm{C}$ ?" Met Office. www.metoffice.gov.uk/research/news/2018/ how-much-co2-at-1.5c-and-2c.

Minx JC et al (2018) Negative emissions-Part 1: research landscape and synthesis. Environ Res Lett 13(6):063001

Moomaw W (2017) To curb climate change, we need to protect and expand US forests. The Conversation 13:063001

Moomaw WR, Masino SA, Faison EK (2019) Intact forests in the United States: Proforestation Mitigates climate change and serves the greatest good. Front For Global Change 2:27

Morrow DR, Buck HJ, Burns WCG, Nicholson S, Turkaly C (2018) Why talk about carbon removal?. Institute for Carbon Removal Law and Policy, American University, Washington, DC

Muffett C, Feit S (2019) Fuel to the Fire; how geoengineering threatens to entrench fossil fuels and accelerate the climate crisis. Center for International Environmental Law (CIEL)

Mufson S (2019) A climate change solution slowly gains ground. Washington Post

Mulligan J, Ellison G, Levin K, McCormick C (2018a) Technological carbon removal in the United States. World Resources Institute

Mulligan J, Ellison G, Gasper R, Rudee A (2018b) Carbon removal in forests and farms in the United States. World Resources Institute

Mulligan J, Ellison G, Levin K (2018c) Foundational questions on carbon removal in the United States. World Resources Institute

Nagabhushan D, Waltzer K (2016) The emission reduction benefits of carbon capture utilization and storage using $\mathrm{CO}_{2}$ enhanced oil recovery. Clean Air Task Force.

Nagabhushan D, J Thompson J (2019) Carbon capture \& storage in the United States Power Sector; The impact of 45Q Federal Tax Credits. Clean Air Task Force

National Academies of Sciences, Engineering, and Medicine (2015) Climate intervention: carbon dioxide removal and reliable 
sequestration. National Research Council, The National Academies Press, Washington, DC

National Academies of Sciences, Engineering, and Medicine (2018) Negative emissions technologies and reliable sequestration: a research agenda. The National Academies Press, Washington, DC

National Academies of Sciences, Engineering, and Medicine (2019) Negative emissions technologies and reliable sequestration: a research agenda. The National Academies Press, Washington, DC

National Resources Defense Council (2007) Supreme court: heattrapping carbon dioxide is pollution. NRDC

Nature Conservancy (2016) Natural climate solutions: transforming land use to curb climate change

Nemet et al (2018) Negative emissions-Part 3: innovation and upscaling. Environ Res Lett 13(2018):063003

North M, Styring P (2015) Perspectives and visions on $\mathrm{CO}_{2}$ capture and utilisation. R Soc Chem

Nunez-Lopez V, Gil-Egui R, Hosseini SA (2019) Environmental and operational performance of CO2-EOR as a CCUS technology. Energies 12:448

Nunez-Lopez V, Moskal E (2019) Potential of CO2-EOR for nearterm decarbonization. Front Clim. https://doi.org/10.3389/fclim .2019 .00005

Offe C (2010) Shared social responsibility: reflections on the need for and supply of 'responsible' patterns of social reform. Transit 40:86-104

Oil and Gas Climate Initiative (2019) Joint declaration on accelerating the CCUS industry

Oil Change International (2017) Expanding subsidies for $\mathrm{CO}_{2}$-enhanced oil recovery: a net loss for communities, taxpayers, and the climate

ourworldindata.org (undated) https://ourworldindata.org/co2-and-other -greenhouse-gas-emissions\#cumulative-co2-emissions

Page B (2020) US leads new wave of carbon capture and storage deployment. The Hill

Parsons RJ (2018) We must challenge capitalist attempts at 'solutions' to climate change. Truthout

Peters A (2019) We have the tech to suck $\mathrm{CO}_{2}$ from the air-but can it suck enough to make a difference? Fastcompany

Pielke Jr. R (2018) Opening up the climate policy envelope. Issues Sci Technol XXXIV(4)

Pigeon J (2019) Underground as a controversial mitigation of climate change option: example of carbon capture and storage (ccs) implementation. reseaerchgate.net

Ranjan M, Herzog HJ (2011) Feasibility of air capture. Energy Procedia 4:2869-2876

Ranson S, Stewart J (1989) Citizenship and government: the challenge for management in the public domain. Polit Stud 37(1):5-24. https://doi.org/10.1111/j.1467-9248.1989.tb00262.x

Rathi A (2018) Climeworks has opened up a third plant capturing carbon dioxide from the air qz.com

Rathi A (2019) You can now pay to turn your carbon emissions to stone. qz.com

Realmonte G et al (2019) An inter-model assessment of the role of direct air capture in deep mitigation pathways. Nat Commun 10:3277

Rhodium Group (Larsen, John, Whitney Herndon, Mikhail Grant \& Peter Marsters) (2019) Capturing leadership. Policies for the US to advance direct air capture technology, Rhodium Group

Romm J (2008) What is the safe upper limit for atmospheric $\mathrm{CO}_{2}$ ? Grist

Rumpel C, Amiraslani F, Koutika LS, Smith P, Whitehead D, Wollenberg E (2018) Put more carbon in soils to meet Paris climate pledges. Nature 564:32-34

Sandalow et al (2017) Carbon Dioxide Utilization (CO2U); ICEF Roadmap 2.0. Innovation for Cool Earth Forum
Schäfer S et al (eds) (2015) Removing greenhouse gases from the atmosphere and reflecting sunlight away from earth. The European Transdisciplinary Assessment of Climate Engineering (EUTRACE)

Schlissel D, Wamsted D (2018) Holy grail of carbon capture continues to elude coal industry. Institute for Energy Economics and Financial Analysis

ScottMadden Management Consultants (2018) Billion dollar Petra Nova coal carbon capture project a financial success but unclear if it can be replicated. ScottMadden

Scripps Institution of Oceanography (2020) Rise of carbon dioxide unabated. https://scripps.ucsd.edu/news/rise-carbon-dioxideunabated

SEI, IISD, ODI, Climate Analytics, CICERO, and UNEP (2019) The Production Gap: the discrepancy between countries' planned fossil fuel production and global production levels consistent with limiting warming to $1.5^{\circ} \mathrm{C}$ or $2^{\circ} \mathrm{C}$

Sekera JA (2016) The public economy in crisis; a call for a new public economics. Springer, New York

Sekera J (2017) Missing from the mainstream: the biophysical basis of production and the public economy.Real-World Econ Rev (81)

Seto CJ, McRae GJ (2011) Reducing risk in basin scale $\mathrm{CO}_{2}$ sequestration: a framework for integrated monitoring design. Environ Sci Technol 45(3):845-859. https://doi.org/10.1021/es102 240w

Sgouridis S, Carbajales-Dale M, Csala D, Chiesa M, Bardi U (2019) Comparative net energy analysis of renewable electricity and carbon capture and storage. Nat Energy 4:1

Smith P (2016) Soil carbon sequestration and biochar as negative emissions technologies. Global Change Biol

Smith P, Davis SJ, Creutzig F, Fuss S, Minx J, Gabrielle B, Kato E et al (2016) Biophysical and economic limits to negative $\mathrm{CO}_{2}$ emissions. Nat Clim Change 6(1):42-50

Smith P et al (2019) How to measure, report and verify soil carbon change to realize the potential of soil carbon sequestration for atmospheric greenhouse gas removal. Glob Change Biol

Socolow R et al (2011)Direct air capture of $\mathrm{CO}_{2}$ with chemicals: a technology assessment for the APS panel on public affairs. American Physical Society

Soltoff B (2019) Inside ExxonMobil's hookup with carbon removal venture Global Thermostat. www.greenbiz.com

State $\mathrm{CO}_{2}$-EOR Deployment Work Group (2017) 21st century energy infrastructure: policy recommendations for deployment of American $\mathrm{CO}_{2}$ pipeline networks

Stewart RJ, Haszeldine S (2014) Carbon accounting for carbon dioxide enhanced oil recovery. Scottish Carbon Capture \& Storage

Stewart RJ Haszeldine S (2015) Can producing oil store carbon? Greenhouse Gas footprint of CO2EOR, offshore North Sea. Environmental Science \& Technology, manuscript

Storrow B (2020) An oil company wants to take $\mathrm{CO}_{2}$ from air. Here's why. www.eenews.net. Accessed 7 Feb 2020

Stretton H, Orchard L (1994) Public goods, public enterprise, public choice- the theoretical foundations for the contemporary attack on government. St. Martin's, New York

Studenski P (1939) Government as a producer. Ann Am Acad Polit Soc Sci 206:23-34

Suebsiri J, Wilson M, Tontiwachwuthikul P (2006) Life-cycle analysis of $\mathrm{CO} 2 \mathrm{EOR}$ on EOR and geological storage through economic optimization and sensitivity analysis using the Weyburn unit as a case study. Ind Eng Chem Res 45:2483-2488

Tabuchi H (2019) Under fire, oil giants mount a defense. New York Times

Temple J (2019a) One man's two-decade quest to suck greenhouse gas out of the sky. MIT Technology Review

Temple J (2019b) Another major oil company tiptoes into the carbon removal space. MIT Technology Review 
The Economist (2009) The illusion of clean coal' and 'carbon capture and storage: trouble in store. Briefing

Townsend A, Havercroft I (2019) The LCRF and CCS protocol: an overview for policymakers and project developers. Global CCS Institute

U.S. Dept. of Energy (2010) Executive summary: report of the interagency task force on carbon capture and storage. https://www. energy.gov/fe/services/advisory-committees/interagency-taskforce-carbon-capture-and-storage

U.S. Department of Energy (2016) Carbon capture, utilization and storage: climate change, economic competitiveness, and energy security

U.S. Department of Energy - U. S. Department of Agriculture (2020) Supporting the next generation of CCUS projects: highlights of the USDA-DOE collaboration. webinar hosted by US Energy Association

U.S. Department of Energy and National Energy Technology Laboratory (2010) Carbon dioxide enhanced oil recovery. DOE \& NETL, U.S

U.S. Department of Energy (2017) Two DOE-supported projects receive awards for carbon capture technologies

U.S. Energy Information Administration (2020) What are U.S. energyrelated carbon dioxide emissions by source and sector? https:// www.eia.gov/tools/faqs/faq.php?id=75\&t $\equiv$ Accessed 26 May 2020

U.S. Energy Information Administration (EIA) (2020) FAQs. How much carbon dioxide is produced per kilowatthour of U.S. electricity generation?. https://www.eia.gov/tools/faqs/faq. php?id=74\&t=11 Accessed 25 June 2020

U.S. Senate Committee on Energy and Natural Resources (2019) U.S. Senate Committee on Energy and Natural Resources. Manchin And Bipartisan Group of Senators Urge Support for DOE Carbon Capture Technology Programs - Democratic News - Newsroom U.S. Senate Committee on Energy and Natural Resources

van Renssen S (2020) Carbon removal enters mainstream climate debate. https://revolve.media/. Accessed 17 Mar 2020

Vasudevan $\mathrm{S}$ et al (2016) Energy penalty estimates for $\mathrm{CO}_{2}$ capture: comparison between fuel types and capture-combustion modes. Energy 103:709-714. https://doi.org/10.1016/j.energ y.2016.02.154

van't Veld K, Manson CF, Leach A (2013) The economics of $\mathrm{CO}_{2}$ sequestration through enhanced oil recovery. ScienceDirect; Energy Procedia 37:6909-6919

Vidal J (2018) How Bill Gates aims to clean up the planet. The Guardian

Wettengel J (2019) Renewables supplied 40 percent of net public power in Germany in 2018. https://www.cleanenergywire.org/. Accessed 2 Jan 2019

Whitehouse S, Slevin J (2020) Carbon pricing represents the best answer to our climate danger. Washington Post

Wong R et al (2013) Net greenhouse gas impact of storing CO2 through enhanced oil recovery. Pembina Institute, Calgary

World Economic Forum (2019) Chart of the day: these countries create most of the world's $\mathrm{CO}_{2}$ emissions. https://www.weforum.org/ agenda/2019/06/chart-of-the-day-these-countries-create-most-ofthe-world-s-co2-emissions/

Wright M (2017) Coastal wetlands excel at storing carbon. https:// umdrightnow.umd.edu/. Accessed 3 Feb 2017

Wuyts M (1992) Deprivation and public need. In: Macintosh M, Wuyts M (eds) Development policy and public action. Oxford University, Oxford, pp 13-38

Zahasky C, Krevor S (2020) Global geologic carbon storage requirements of climate change mitigation scenarios. Energy Environ Sci 13:1561-1567. https://doi.org/10.1039/d0ee00674b
Zomer RJ et al (2016) Global tree cover and biomass carbon on agricultural land: the contribution of agroforestry to global and national carbon budgets. Nat Sci Rep 6:29987

Zomer RJ, Bossio DA, Sommer R, Verchot LV (2017) Global sequestration potential of increased organic carbon in cropland soils. Sci Rep 7:15554. https://doi.org/10.1038/s41598-017-15794-8

\section{Further Reading}

All Party Parliamentary Climate Change Group (2019) Negative emissions technologies: a necessary step or a false hope? Panel discussion, APPCCG: Naomi Vaughan, Charlotte Morgan, David Reiner

Ash K et al (2015) Carbon capture scam (CCS). Greenpeace

Ayres R (2016) Energy, complexity and wealth maximization. Springer, New York

Azzolina NA et al (2017) A life cycle analysis of incremental oil produced via $\mathrm{CO}_{2}$ EOR. Energy Procedia 114:6588-6596

Azzolina NA et al (2015) $\mathrm{CO}_{2}$ storage associated with $\mathrm{CO}_{2}$ enhanced oil recovery: a statistical analysis of historical operations. Int $\mathrm{J}$ Greenhouse Gas Control 37:384-397

Carbon Capture Coalition (2019) Carbon Capture Coalition Hails Bipartisan Introduction of the USE IT Act in the U.S. House of Representatives Today. Carbon Capture Coalition Legislation Team

Christensen J (2018) Three things to know about changes to the 45Q tax credit for carbon capture and storage projects. Great Plains Institute

Clean Water Fund (2018) Carbon dioxide enhanced oil recovery $\left(\mathrm{CO}_{2}\right.$-EOR). CWF Protect Water and Communities from Oil and Gas Campaign

Cleveland CJ (1987) Biophysical economics: historical perspective and current research trends. Ecol Model 38:47-73 (Note: this paper summarizes works by Howard Odum, Nicholas Georgescu-Roegen, Herman Daly and other pioneers in the field)

Cleveland CJ, Costanza R, Hall CAS, Kaufmann R (1984) Energy and the U.S. economy: a biophysical perspective. Science 225:890

Codur A-M, Watson J (2018) Climate smart or regenerative agriculture? Defining new climate policies based on soil health. Tufts Global Development and Environment Institute, Climate Policy Brief \#9

Cohn G (1895) The science of finance, Veblen TB, trans. University of Chicago Press.

Costanza R (1980) Embodied energy and economic valuation. Science 210:1219

Daly HE (1998) Consumption: value added, physical transformation, and welfare. Ethics of consumption: the good life, justice, and global stewardship. Rowman and Littlefield, Lanham

Daly HE (2007) Ecological economics and sustainable development; selected essays of herman daly. MPG Books Ltd., Bodmin

Davies G (2018) Maximizing carbon storage and climate resiliency in wetland restoration and creation-an innovative approach, and why it matters. Tufts Global Development and Environment Institute, Lecture

DeCicco J (2018) Biofuels versus biodiversity ad the need to think beyond carbon neutral. University of Michigan, Beyond carbon neutral seminar series, ppt.

Dennis B, Mooney C (2018) Global greenhouse gas emissions will hit yet another record high this year, experts project. Washington Post

Dunne D (2017) Tropical forests are 'no longer carbon sinks' because of human activity. CarbonBrief

Eide J, Herzog H, Webster M (2013) Rethinking CCS Developing quantitative tools for analyzing investments in CCS. Energy Procedia $37: 7647$ 
Energy Action Coalition (2014) Enhanced oil recovery is NOT carbon sequestration. Energy Justice Network

Esken A et al (2010) Comparison of renewable energy technologies with carbon dioxide capture and storage (CCS). Wuppertal Institute for Climate, Environment and Energy

Field CB, Mach KJ (2017) Rightsizing carbon dioxide removal. Science 356(6339):706-707

Galaz V et al (2018) Finance and the Earth system—exploring the links between financial actors and non-linear changes in the climate system. Global Environ Chall 53:296

Gates B (2019) How we'll invent the future. MIT Technology Review

Global CCS Institute (2019a) Oxy and carbon engineering partner to combine direct air capture and enhanced oil recovery storage. Global Carbon Capture and Storage Institute

Grandoni D (2020) House democrats tee up sweeping climate bill as alternative to Green New Deal. Washington Post

Hall CAS, Klitgaard KA (2012) Energy and the wealth of nations. Springer, New York

Hall CAS, Cleveland CJ, Kaufmann R (1986) Energy and resource quality: the ecology of the economic process.Wiley, New York (Second Edition. University Press of Colorado).

Hall CAS, Lindenberger D, Kummel R, Kroeger T, Eichorn W (2001) The need to reintegrate the natural sciences with economics. Bioscience 51(8):663

Hansen J et al (2017) Young people's burden: requirement of negative CO2 emissions. Earth Syst Dyn 8:577-616

Harvey C (2018) $\mathrm{CO}_{2}$ emissions reached an all-time high in 2018. Sci Am

Haszeldine S, Scott V (2014) Storing carbon for geologically long timescales to engineer climate. In: Hester RE, Harrison RM (eds) Geoengineering of the climate system.

Hawes C (2019) New $\mathrm{CO}_{2}$ capture technology is not the magic bullet against climate change. greenbiz.com

Heinberg R (2018) The new IPCC report offers climate solutions that depend on magic. Pacific Standard

Herzog HJ (2018) Why we can't reverse climate change with 'negative emissions technologies'. The Conversation

Hu B, Zhai H (2017) The cost of carbon capture and storage for coal-fired power plants in China. Int J Greenhouse Gas Control 65:23-31

Intergovernmental Panel on Climate Change (1990) Climate change: the IPCC scientific assessment. Cambridge University Press, Cambridge

Intergovernmental Panel on Climate Change (2001) The carbon cycle and atmospheric carbon dioxide", Chp 3 in climate change 2001: the scientific basishttps://www.ipcc.ch/site/assets/uploa ds/2018/02/TAR-03.pdf

Intergovernmental Panel on Climate Change (2014a) Climate change 2014: synthesis report. Contribution of working groups I, II and III to the fifth assessment report of the intergovernmental panel on climate change

Intergovernmental Panel on Climate Change (2018b) Global warming of $1.5^{\circ} \mathrm{C}$ : an IPCC special report on the impacts of global warming. WMO, UNEP

Intergovernmental Panel on Climate Change (2018c) Mitigation pathways compatible with $1.5^{\circ} \mathrm{C}$ in the context of sustainable development (In Press)

Jiang et al (2016) Life cycle $\mathrm{CO}_{2}$ emission estimation of CCSEOR system using different $\mathrm{CO}_{2}$ sources. Pol J Environ Stud 27(6):2573-2583

Keith DW (2001) Industrial carbon management: an overview. In: Carbon management: implications for R\&D in the chemical sciences and technology. The National Academies Press, Washington DC
Langley C (2018) Creating negative emissions: the role of natural and technological carbon dioxide removal strategies. Climate Advisers

Le Quere C et al (2018) Global carbon budget 2018. Earth Syst Sci Data 10:2141-2194

Levin K, Mulligan J, Ellison G (2018)Taking greenhouse gases from the sky: 7 things to know about carbon removal. World Resources Institute

Lindsey R (2019) Climate change: atmospheric carbon dioxide. https ://www.climate.gov/news-features/understanding-climate/clima te-change-atmospheric-carbon-dioxide.

Markusson N, McLaren D, Willis R (2020) "Mitigation Deterrence" webinar April 28, 2020, sponsored by the Institute for Carbon Removal Law \& Policy, American University

McGlade C (2019) Carbon capture: can $\mathrm{CO}_{2}$-EOR really provide carbon-negative oil? Energy Post

Moomaw W, Smith D (2017) The Great American Stand; US Forests and the Climate Emergency 2017

Moomaw W, Chmura GL, Davies G, Finlayson CM, Middleton BA, Natali SM, Perry JE, Roulet N, Sutton-Grier AE (2018a) Wetlands in a changing climate: science, policy and management. Wetlands 38:183

Moomaw W, Davies G, Finlayson M (2018b) What the world needs now to fight climate change: more swamps. The Conversation

Mooney C, Dennis B (2019) Global greenhouse gas emissions will hit yet another record high this year. Washington Post

Morgan G (2019) Chevron, Occidental buy stake in carbon capturing firm backed by Bill Gates and Murray Edwards. Financial Post

Nahlik AM, Fennessy MS (2016) Carbon storage in U.S. Wetlands. Nat Commun 7:13835

National Energy Technology Laboratory (2009) Carbon dioxide enhanced oil recovery; untapped domestic energy supply and long term carbon storage solution. United States Department of Energy

National Law Review (2019) Implementation of recent amendments to the $45 \mathrm{Q}$ carbon sequestration tax credit. The National Law Review

NOAA (2019) Carbon dioxide levels hit record peak in May. https ://research.noaa.gov/article/ArtMID/587/ArticleID/2461/Carbo n-dioxide-levels-hit-record-peak-in-May

Noel J (2018) Carbon capture and release: oversight failures in Section 45Q tax credit for enhanced oil recovery. Clean Water Action

Redman J (2017) Expanding subsidies for $\mathrm{CO}_{2}$-enhanced oil recovery: a net loss for communities, taxpayers, and the climate. Oil Change International

Roberts D (2019) Could squeezing more oil out of the ground help fight climate change? Vox

Scheer K, Ulland L et al (2009) A landowner's guide to carbon sequestration credits. Central Minnesota Regional Sustainable Development Partnership

Snaebjornsdottir SO et al (2020) Carbon dioxide storage through mineral carbonation. Nature 1:1

Von der Assen N, Jung J, Bardow A (2013) Life-cycle assessment of carbon dioxide capture and utilization: avoiding the pitfalls. Energy Environ Sci 6(9):2721

Von der Assen N, Voll P, Peters M, Bardow A (2014) Life cycle assessment of $\mathrm{CO}_{2}$ capture and utilization: a tutorial review. Chem Soc $\operatorname{Rev} 43: 7982$

Publisher's Note Springer Nature remains neutral with regard to jurisdictional claims in published maps and institutional affiliations. 